Revue des patrimoines

$34 \mid 2018$

Lieux de pouvoirs. Architectures administratives dans la France contemporaine, 1945-2013. Avant/Après la décentralisation

\title{
L'architecture à la reconquête de sa dimension symbolique ? Architectures et lieux de pouvoir à l'heure de la décentralisation à Marseille (1984-1994)
}

Architecture in search of its symbolic dimensions? Architecture and places of power at Marseilles in a time of decentralization (1984-1994)

\section{Éléonore Marantz}

\section{(2) OpenEdition}

Journals

Édition électronique

URL : http://journals.openedition.org/insitu/15743

DOI : $10.4000 /$ insitu. 15743

ISSN : 1630-7305

Éditeur

Ministère de la culture

Référence électronique

Éléonore Marantz, «L'architecture à la reconquête de sa dimension symbolique ? Architectures et lieux de pouvoir à l'heure de la décentralisation à Marseille (1984-1994) », In Situ [En ligne], 34 | 2018, mis en ligne le 04 mai 2018, consulté le 19 avril 2019. URL : http://journals.openedition.org/insitu/15743 ; DOI : 10.4000/insitu. 15743

Ce document a été généré automatiquement le 19 avril 2019

\section{(i) $\odot$}

In Situ Revues des patrimoines est mis à disposition selon les termes de la licence Creative Commons Attribution - Pas d'Utilisation Commerciale - Pas de Modification 4.0 International. 


\section{L'architecture à la reconquête de sa dimension symbolique? Architectures et lieux de pouvoir à l'heure de la décentralisation à Marseille (1984-1994)}

Architecture in search of its symbolic dimensions? Architecture and places of power at Marseilles in a time of decentralization (1984-1994)

Éléonore Marantz

Dans les grandes métropoles régionales françaises, à partir du milieu des années 1980, les cadres de production, les programmes et les formes de l'architecture publique se renouvellent sous l'effet conjugué des lois de décentralisation (1982-1986) qui justifient la construction de nouveaux bâtiments ${ }^{1}$ et de la loi sur la maîtrise d'ouvrage publique (loi MOP, 1985) qui impose le concours d'architecture comme mode de sélection des architectes. 
Figure 1

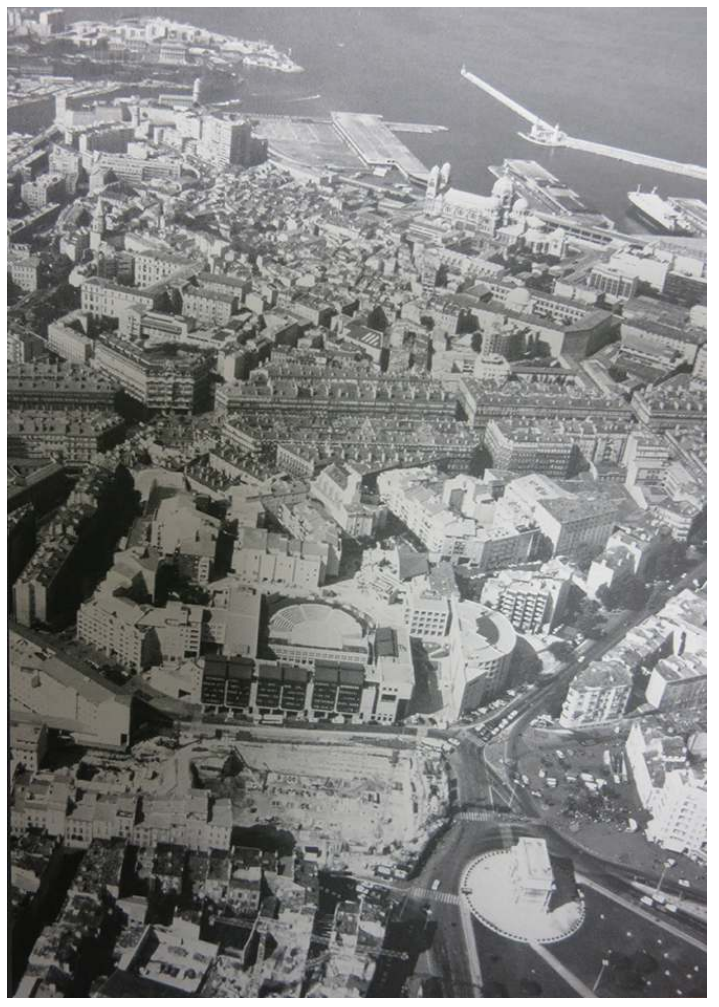

Hôtel de région de PACA (1984-1986, arch. : Jean-Michel Battesti ; 1987-1991, arch. : Claude Parent Christian Biaggi, Bruno Maurin). Vue aérienne, s.d. circa 1991 (AD BdR Delta 7408).

(C) Archives départementales des Bouches-du-Rhône (AD BdR).

Figure 2

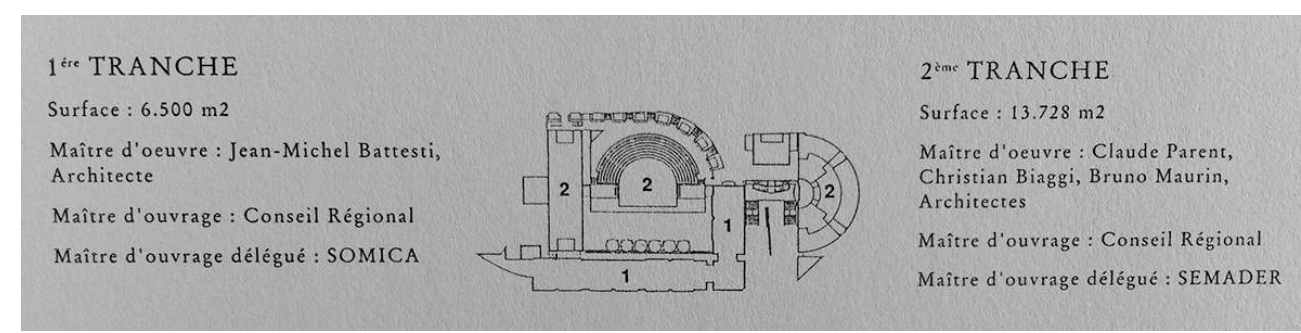

Hôtel de région de PACA. Plan schématique de répartition des bâtiments par tranche d'exécution (ARPACA 4445 W 3).

(C) Archives de la région PACA (ARPACA).

2 À Marseille, cette décennie voit la construction d'un nouvel hôtel de région réalisé en deux tranches (1984-1986, arch. : Jean-Michel Battesti ; 1987-1991, arch. : Claude Parent, Christian Biaggi, Bruno Maurin) (fig. 1, fig. 2) et d'un hôtel de département (1990-1994, arch.: William Alsop, John Lyall (fig. 3), édifices très différents d'un point de vue architectural mais ayant en commun d'accueillir des collectivités territoriales dont les compétences avaient été récemment définies (ou redéfinies) et de contribuer à la transformation du territoire métropolitain (requalification du quartier de la Butte-auxCarmes pour le premier et de celui de Saint-Just pour le second). 


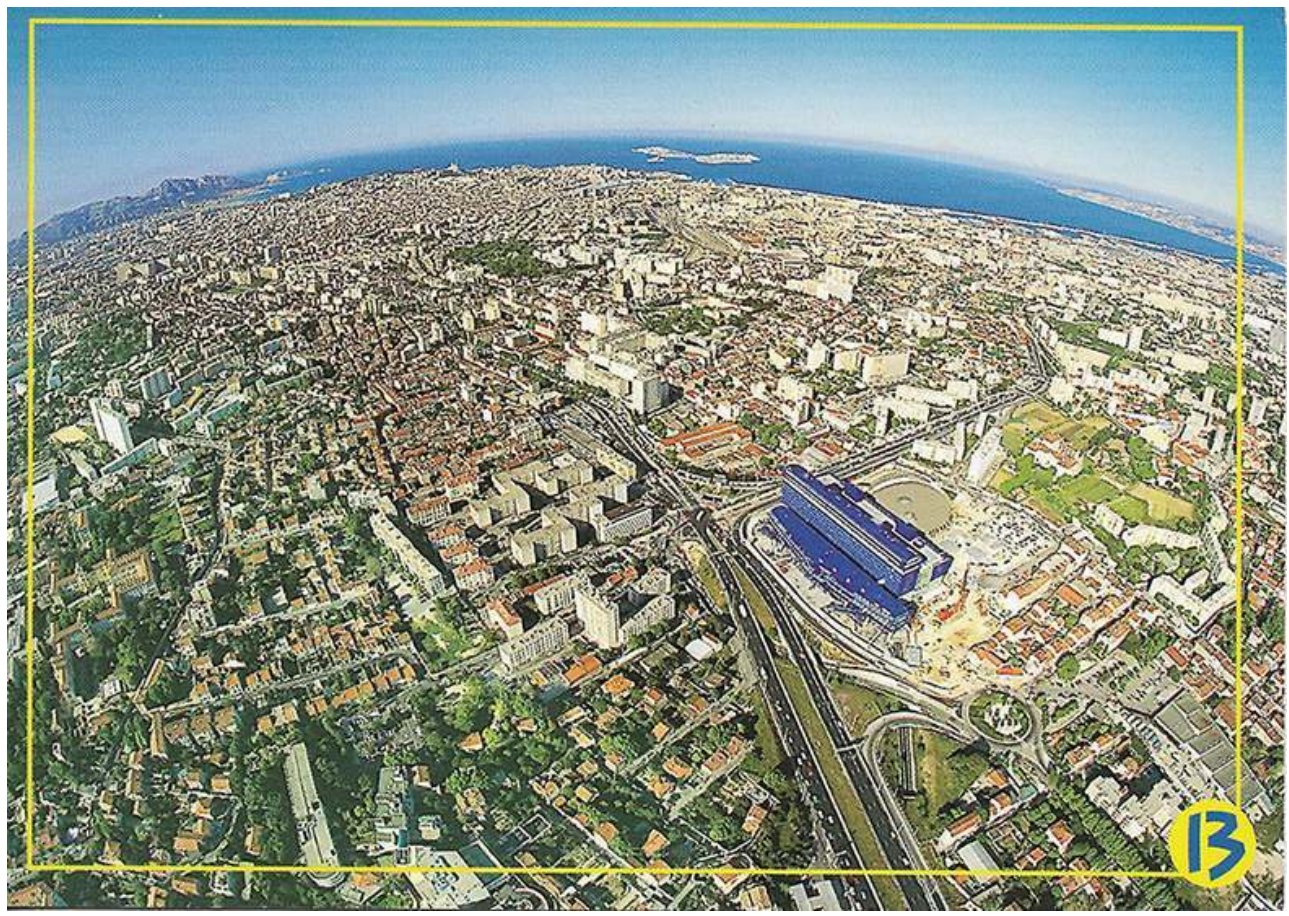

Hôtel de département des Bouches-du-Rhône (1990-1994, arch. : William Alsop, John Lyall). Vue aérienne, carte postale éditée par le conseil général des Bouches-du-Rhône, (AD BdR 2338 W 9). (c) AD BdR.

3 Le contexte marseillais invite à interroger un possible engagement des collectivités territoriales en faveur de l'architecture ou, tout au moins, les modalités d'une reconquête, par les maîtres d'ouvrage comme par les maîtres d'œuvre, de la dimension symbolique de l'architecture au moment où le concept d'équipement public, si prévalent au cours des Trente Glorieuses qu'il avait rendu presque obsolète la notion de monument, tend à s'effacer au profit de celui d'architecture publique. Ce glissement sémantique est-il révélateur de la manière dont les maîtres d'ouvrage se saisissent désormais de l'architecture pour affirmer leur emprise et définir leur image? Cet engagement matériel et symbolique a-t-il des incidences sur l'architecture ${ }^{2}$ ? Les nouveaux hôtels de région et de département construits à Marseille offrent la possibilité de mieux comprendre les phénomènes à l'œuvre au cours d'une décennie qui, à plusieurs titres, apparaît comme décisive dans l'histoire de la production architecturale récente en général, et de l'architecture publique en particulier ${ }^{3}$. Aborder successivement le concours d'architecture comme outil de légitimation pour les collectivités territoriales (I), les modalités d'une reconquête de et par l'architecture (II), puis la dialectique entre rhétorique et architecture (III), permet de le mesurer.

\section{Le concours d'architecture, un outil de légitimation pour les collectivités territoriales}

4 La redéfinition du cadre de la commande publique est une conséquence collatérale - ou un prolongement logique - de la réforme de l'enseignement de l'architecture qui intervient à la fin de l'année 1968. Le décret du 6 décembre procède à l'éclatement de la 
section Architecture de l'École nationale supérieure des beaux-arts (ENSBA) et donne aux écoles régionales leur autonomie pédagogique en fondant des unités pédagogiques d'architecture ${ }^{4}$. Ce décret met ainsi fin à un système de formation mais aussi (et surtout) à un système de sélection et de structuration professionnelles ${ }^{5}$. Avec la suppression du Grand Prix de Rome, et plus généralement des concours de l'École, l'État se trouve dépourvu du principal critère de sélection qui lui permettait de réguler l'accès à la commande publique depuis le XVIII ${ }^{\mathrm{e}}$ siècle $^{6}$. Au cours des années 1970, la question de la qualité des bâtiments publics est portée au centre des débats par toute une série d'actions et de mesures ${ }^{7}$ qui aboutissent en 1977 (loi n 77-2 du 3 janvier 1977) à la création de la Mission interministérielle sur la qualité des constructions publiques (MIQCP), puis à la promulgation de la loi sur la maîtrise d'ouvrage publique (loi no 85-704 du 12 juillet 1985, dite loi MOP). Votée le 12 juillet 1985 mais appliquée systématiquement à partir de 1993 seulement ${ }^{8}$, cette loi impose désormais que, pour tout investissement public de plus de dix millions de francs, soit organisé un concours selon un processus codifié 9 . Conjugué aux lois de décentralisation qui en accélèrent l'application et en amplifient l'écho, ce nouveau dispositif légal d'accès à la commande publique «révolutionne» le monde de l'architecture. Dans l'esprit des acteurs de l'époque, la généralisation des concours doit permettre «d'améliorer la qualité architecturale ${ }^{10}$ » en mettant fin à la politique des « modèles » qui prévalait depuis les années 1950, en suscitant la créativité architecturale, en rendant caducs les monopoles professionnels, en favorisant l'accès des jeunes architectes à la commande et en impliquant davantage la maîtrise d'ouvrage. Le concours d'architecture devient un exercice en soi pour les architectes comme pour les commanditaires. Ceux organisés par le conseil régional de PACA et le conseil général des Bouches-du-Rhône pour concevoir leurs «hôtels » respectifs en témoignent de façon particulièrement explicite: deux collectivités territoriales n'ayant pas la même antériorité historique ${ }^{11}$ appréhendent différemment le concours d'architecture, parce que, en la matière, leurs compétences et leurs objectifs diffèrent.

\section{S'affirmer}

5 Pour le conseil régional ${ }^{12}$, il s'agit d'une expérience inaugurale ${ }^{13}$, aussi recourt-il à un organisme d'assistance à maitrise d'ouvrage qui l'accompagne depuis l'étude d'implantation du nouvel hôtel de région jusqu'à sa livraison ${ }^{14}$, y compris dans l'organisation des concours d'architecture. Le conseil régional opte en effet pour une construction en deux tranches ${ }^{15}$ donnant lieu à deux concours distincts (1984 et 1987). Le concours pour la première tranche, à savoir le bâtiment administratif qui prendra rapidement le nom d'immeuble des Présentines, est en effet un concours restreint à un degré sur avant-projet sommaire (APS, avec maquette au $1 / 200^{\mathrm{e}}$ ). Après un appel à candidatures auprès de plus de cinquante agences d'architecture ${ }^{16}$, la liste des concurrents appelés à concourir est arrêtée à sept candidats, tous locaux à l'exception notable de l'architecte catalan Ricardo Bofill (né en 1939) dont l'empreinte postmoderne marquait déjà quelques villes nouvelles de la région parisienne (Cergy-Pontoise, Marnela-Vallée ou Saint-Quentin-en-Yvelines). En 1984, quand il est approché par le conseil régional de PACA, il est en train de réaliser des opérations d'envergure à Paris et à Montpellier ${ }^{17}$ mais n'a pas encore remporté le concours (jugé le 21 juin 1985) de l'hôtel de région de Languedoc-Roussillon (fig. 4). Finalement, Ricardo Bofill ne participe pas à la seconde phase du concours de l'hôtel de région de PACA qui, de fait, ne met en 
concurrence que six agences - Atelier Sud, Atelier 9, Delta atelier architecture, Battesti, Matteoni, Gros $^{18}$ - à rayonnement régional.

Figure 4

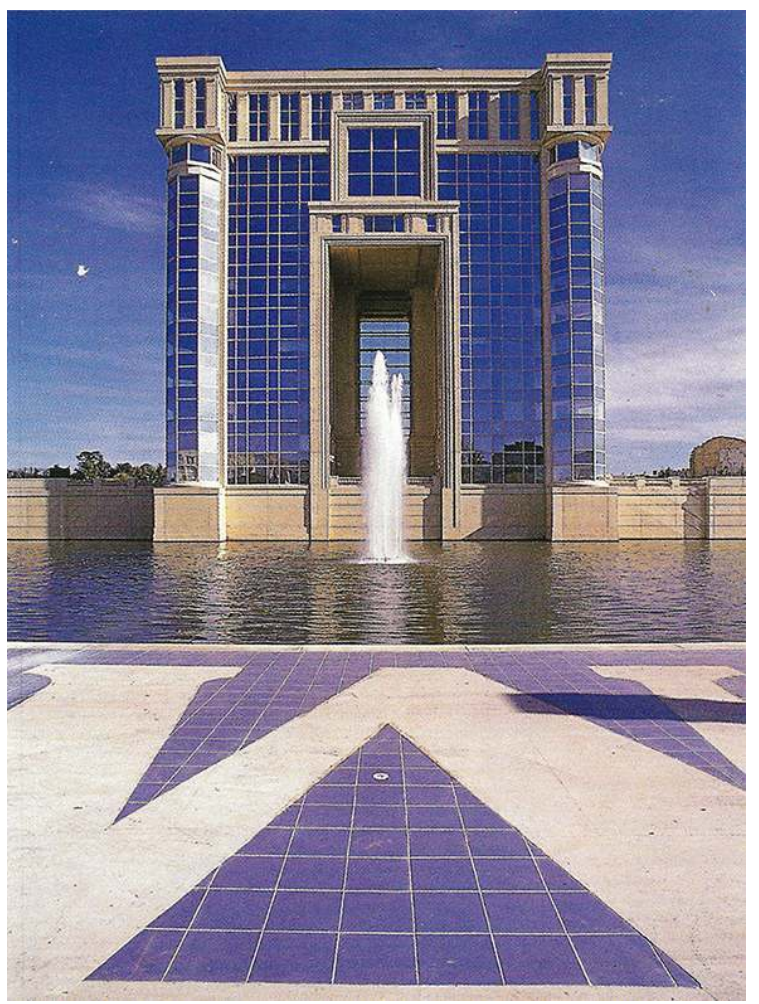

Hôtel de région de Languedoc-Roussillon, Montpellier (1986-1989, arch. : Ricardo Bofill). Vue générale, carte postale, collection de l'auteur.

6 Le 12 novembre 1984, le jury désigne le projet du jeune architecte marseillais Jean-Michel Battesti (fig. 5, 6, 7) comme le «seul (...) que l'on peut retenir » car «conforme au règlement, le mieux adapté au site, fonctionnel, offrant un bon compromis entre le passé historique et l'urbanisme futur et ne nécessitant, pour être mis en œuvre, qu'une mise au point minime $»^{19}$. 
Figure 5

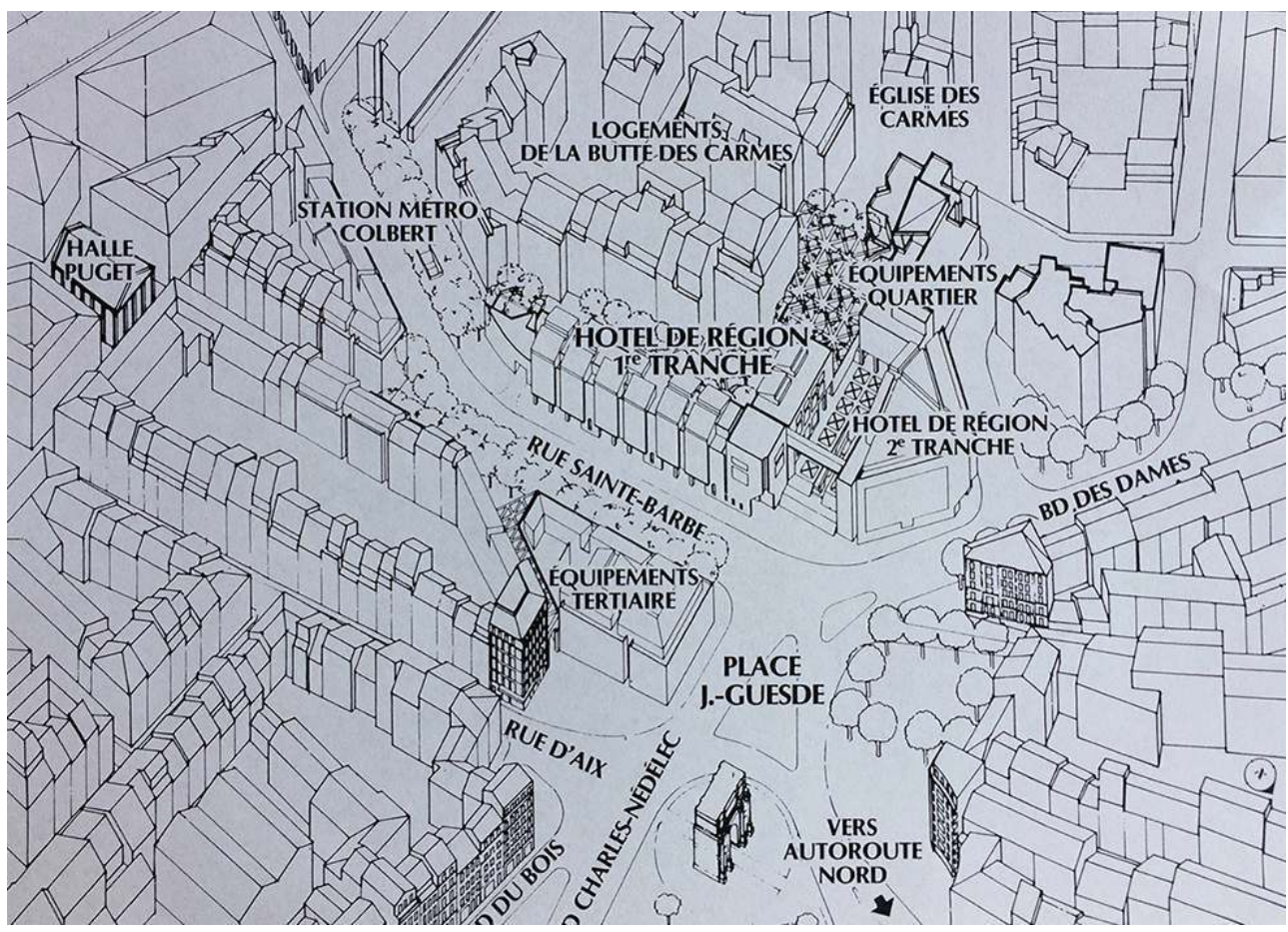

Hôtel de région de PACA. Immeuble des Présentines (1984-1987, arch. : Jean-Michel Battesti) Axonométrie d'ensemble du concours d'architecture (1984, Jean-Michel Battesti), (ARPACAV181-395)

(c) ARPACA.

Figure 6

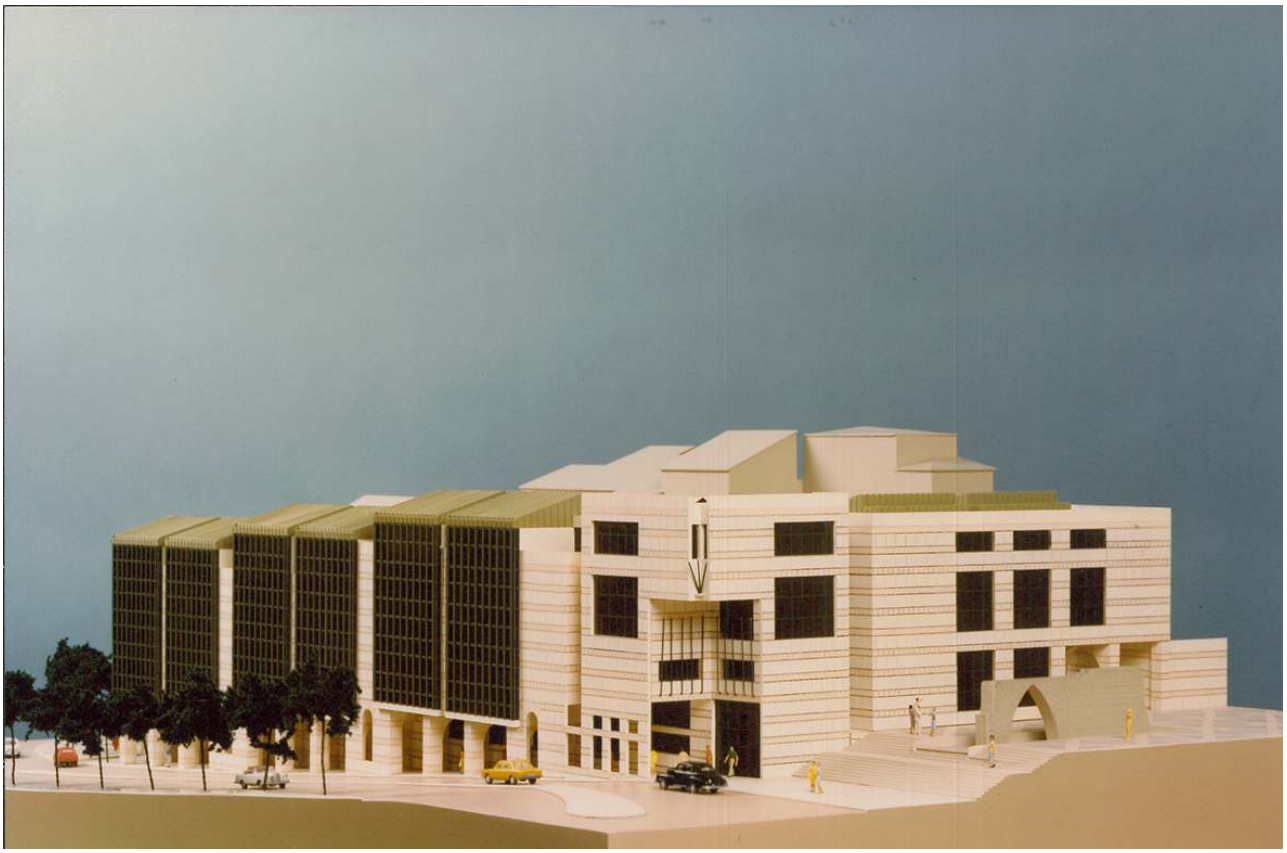

Hôtel de région de PACA. Immeuble des Présentines (1984-1987, arch. : Jean-Michel Battesti) Photographie de la maquette de concours (s.d. circa 1984) (ARPACA 181 B 95).

(c) ARPACA. 
Figure 7

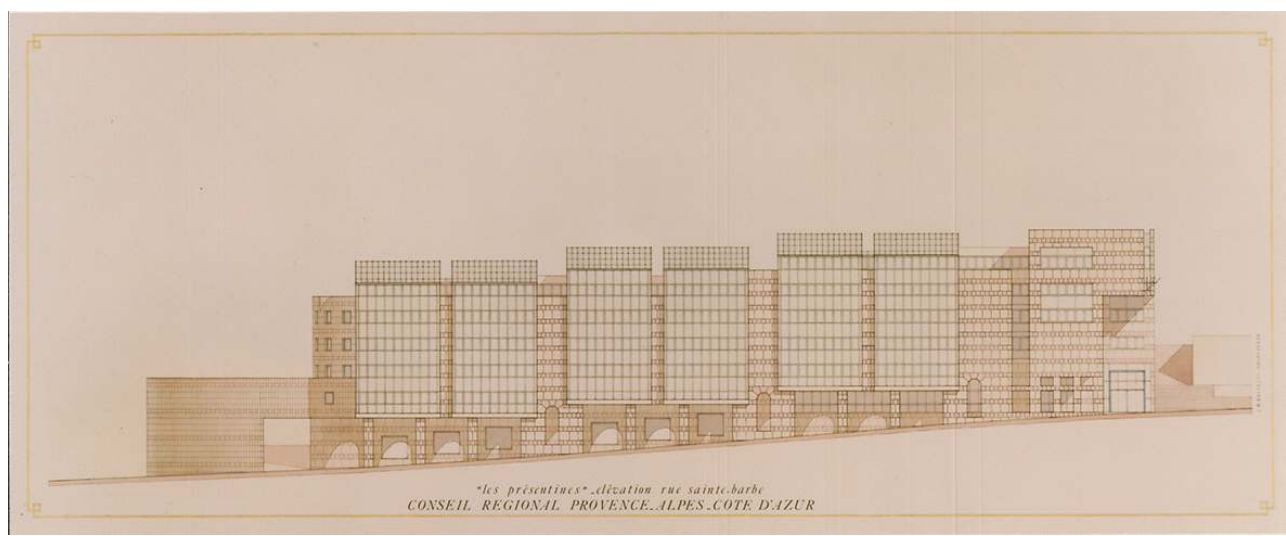

Hôtel de région de PACA. Immeuble des Présentines (1984-1987, arch. : Jean-Michel Battesti) Élévation de la façade sur rue Sainte-Barbe (s.d. circa 1984) (ARPACA 181 B 95).

(c) ARPACA.

7 Michel Pezet, président du conseil régional, avalise ce choix ${ }^{20}$; le permis de construire est accordé le 14 octobre $1985^{21}$ et les travaux commencent. Au début du mois de décembre $1987^{22}$, les services du conseil régional investissent l'immeuble des Présentines (fig. 8). Il est officiellement inauguré le 7 janvier 1988 par Jacques Chaban-Delmas (président de l'Assemblée nationale et du conseil régional d'Aquitaine), en présence de Jean-Claude Gaudin (président du conseil régional de PACA), Robert Vigouroux (maire de Marseille), Louis Philibert (président du conseil général des Bouches-du-Rhône) et Jean Clauzel (préfet). 


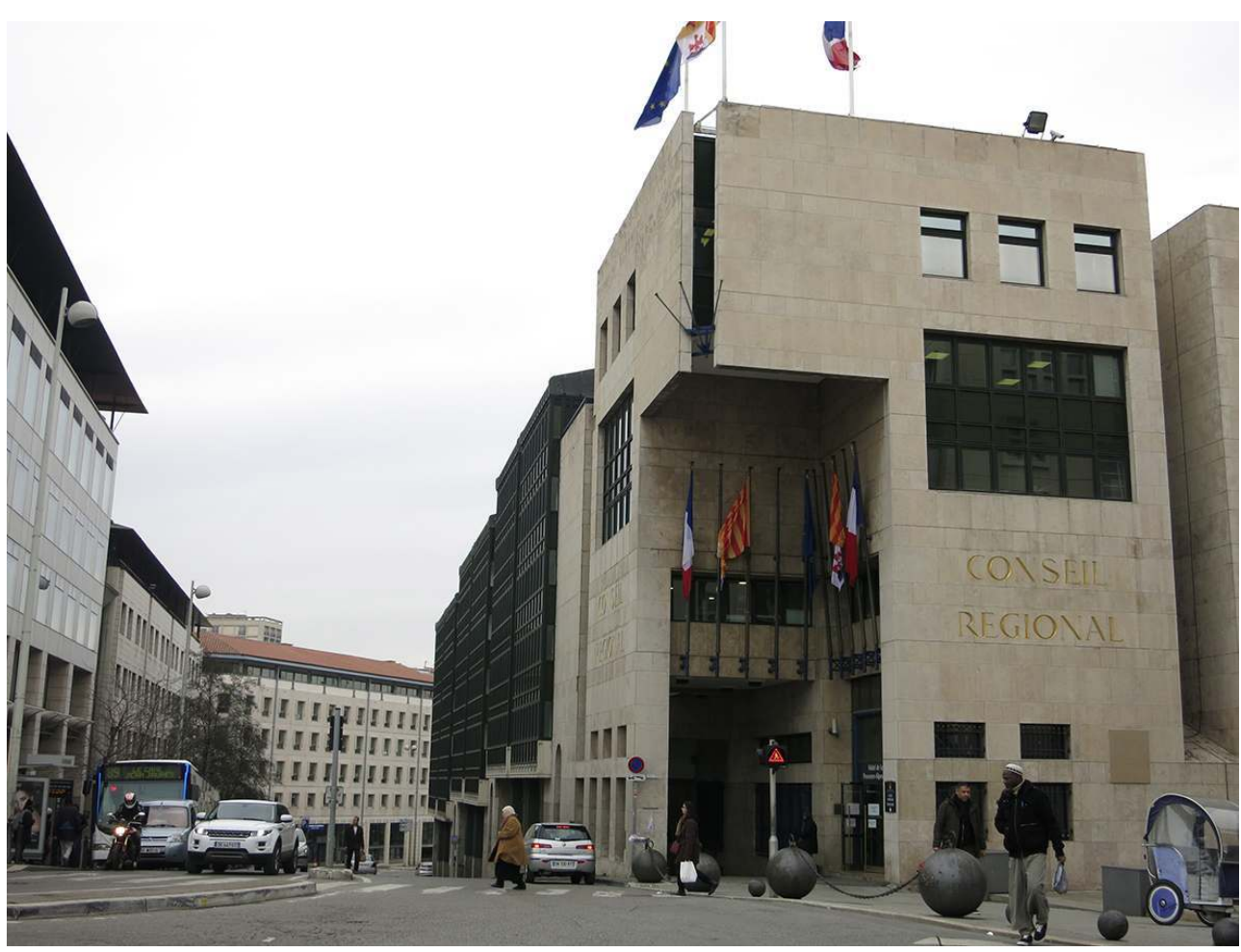

Hôtel de région de PACA. Immeuble des Présentines (1984-1987, arch. : Jean-Michel Battesti). Vue actuelle.

Phot. Éléonore Marantz, 2015. @ Éléonore Marantz.

La veille de l'inauguration, le permis de construire de la seconde tranche de l'hôtel de région - le bâtiment de l'exécutif comprenant notamment la salle de l'assemblée régionale et les bureaux des élus - avait été accordé23 ${ }^{3}$ La conception en revient à Claude Parent (1923-2016), associé pour l'occasion à ses confrères marseillais Christian Biaggi et Bruno Maurin, dont le projet avait été sélectionné le 9 juillet 1987 au terme d'un concours en deux phases: avis public d'appel à candidature puis concours sur esquisse entre six équipes sélectionnées sur références qui étaient toutes, à l'exception notable de l'équipe lauréate, des agences locales ${ }^{24}$. Ce «bloc plénier ", mis en chantier en juillet 1989, sera inauguré en 1991 (fig. 9, 10, 11) mais avant même toute considération architecturale, le processus de sélection des architectes mis en œuvre par le conseil régional de PACA pour construire l'hôtel de région peut être interprété comme une parabole de sa position institutionnelle : par le choix de Jean-Michel Battesti, dont l'immeuble des Présentines est la première réalisation notable, la jeune collectivité territoriale délivre un message de soutien à la jeune architecture marseillaise, sans renoncer, en faisant appel à Claude Parent pour le bâtiment de "représentation " de l'institution, au prestige qu'il y a à s'attacher les services d'un lauréat du Grand Prix national d'architecture (1979) ${ }^{25}$. Le mode opératoire permet assez habilement à la nouvelle collectivité territoriale de se positionner, entre ancrage local et rayonnement national, sur l'échelle institutionnelle et politique, d'affirmer son identité et de mettre en évidence sa sphère d'influence ${ }^{26}$. 
Figure 9

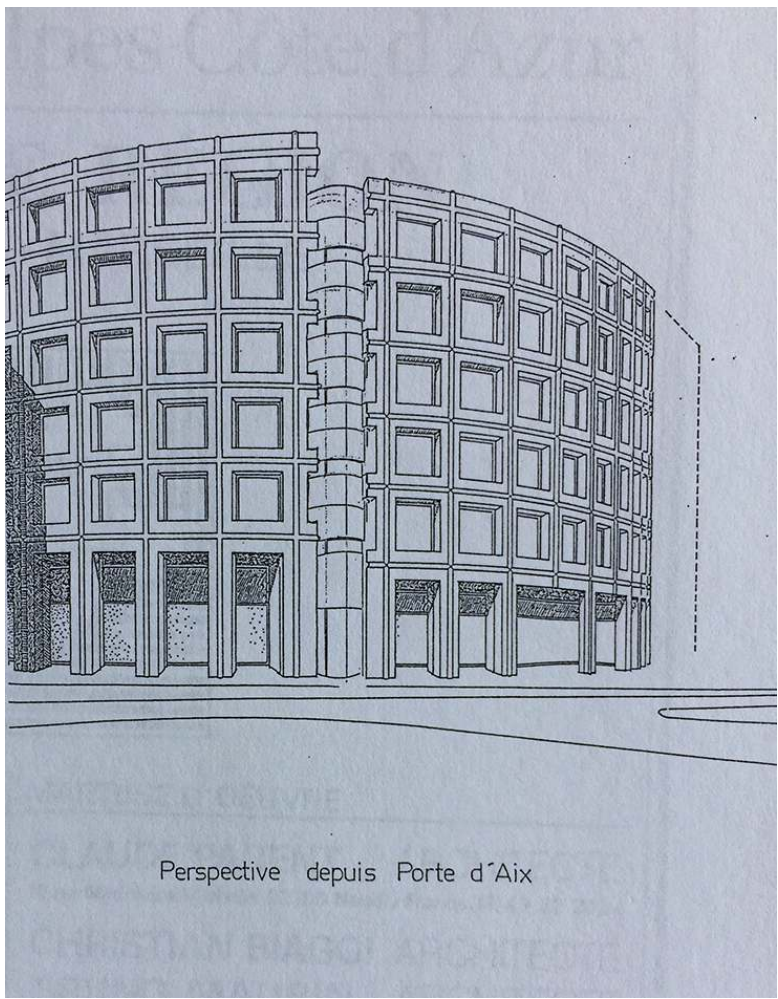

Hôtel de région de PACA. Bloc plénier (1987-1991, arch. : Claude Parent, Christian Biaggi et Bruno Maurin). Perspective depuis la Porte d'Aix (s.d. circa 1987) (ARPACA 35 W 96).

(C) ARPACA. 
Figure 10

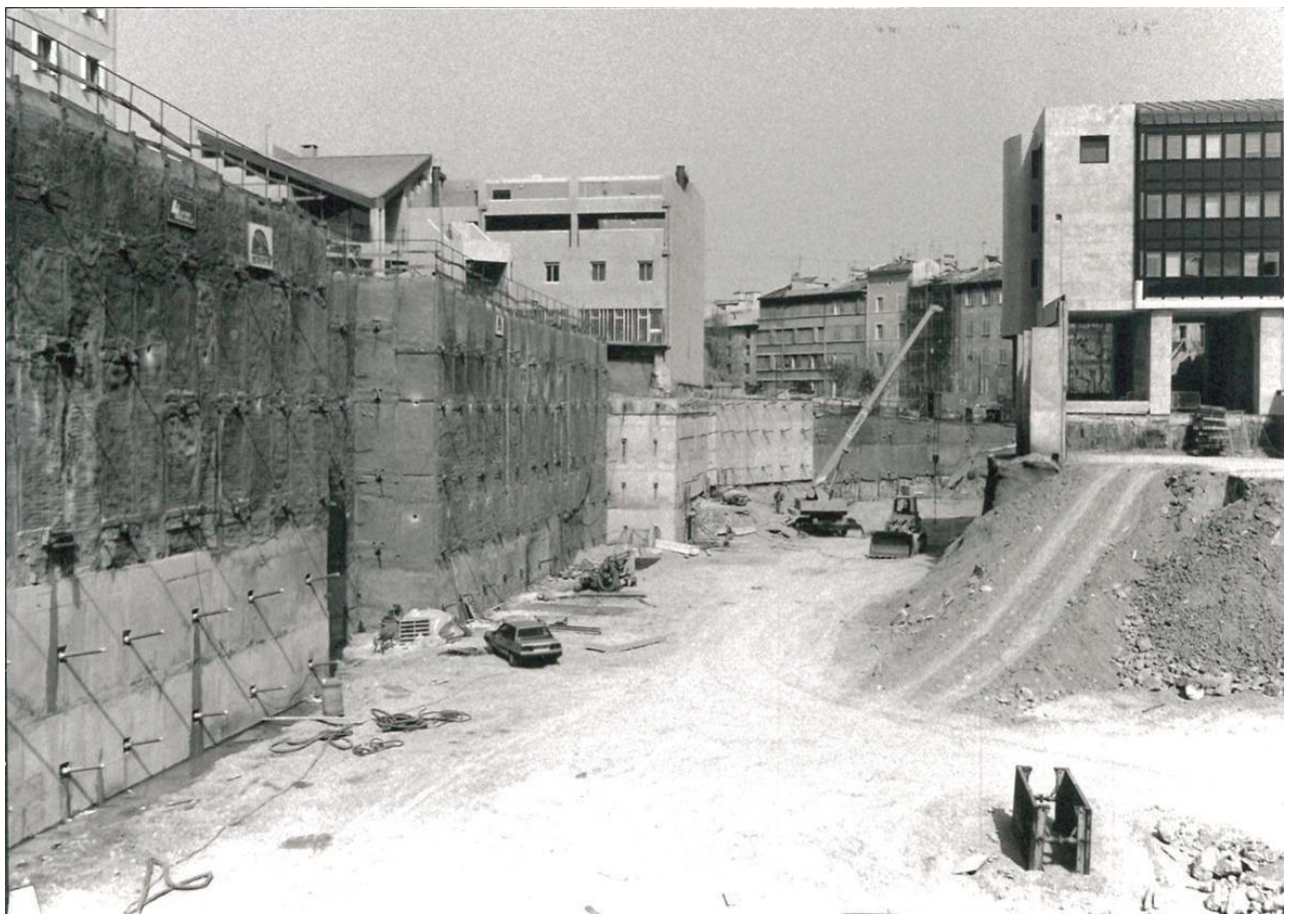

Hôtel de région de PACA. Bloc plénier (1987-1991, arch. : Claude Parent, Christian Biaggi et Bruno Maurin). Photographie de chantier (s.d. circa 1990), (ARPACA 215 W 20B16).

(C) ARPACA. 


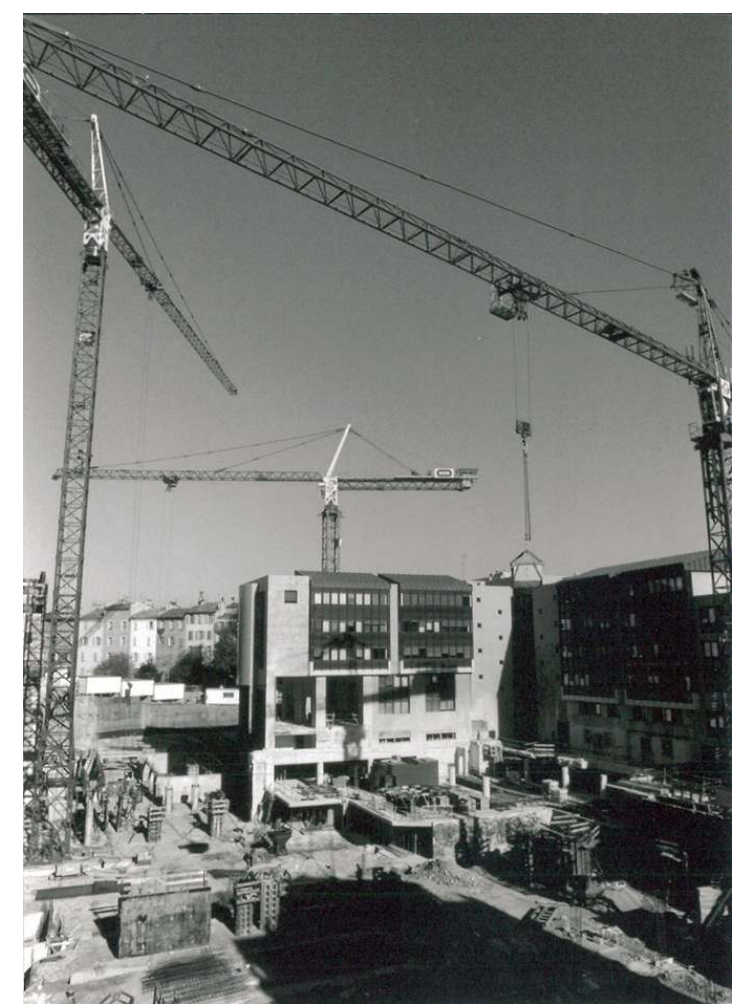

Hôtel de région de PACA. Bloc plénier (1987-1991, arch. : Claude Parent, Christian Biaggi et Bruno Maurin). Photographie de chantier (s.d. circa 1990), (ARPACA 215 W 20B16).

(C) ARPACA.

\section{Se réinventer}

Lorsque quelques années plus tard, le conseil général aborde à son tour l'exercice du concours pour construire le bâtiment qui accueillera ses services, il exprime d'autres objectifs, en raison justement des nouvelles concurrences territoriales induites par les lois de décentralisation. Pour le département, il ne s'agit pas tant d'affirmer son importance à l'échelle locale, entre Ville et Région, présence qu'incarnent déjà de nombreux bâtiments publics, mais de démontrer que son rayonnement peut dépasser ces échelons territoriaux. En conséquence, il lance en mars 1990 un « concours international de concepteurs ", tout à fait dans l'esprit de la loi MOP, auquel prennent part des candidats $^{27}$ de nationalité française (66), italienne (7), anglaise (3), roumaine (6), grecque (1) et belge (1).

10 Le principe retenu est celui d'un concours à deux phases : concours sur esquisse devant aboutir au choix de quatre équipes, puis concours sur APS ${ }^{28}$ (rémunéré à hauteur de 200000 francs par équipe). La dimension internationale et, plus fondamentalement, l'envergure exceptionnelle ainsi que le caractère exemplaire de la consultation, reposent sur la méthode mise en œuvre par une administration rodée à l'exercice ${ }^{29}$. Jacques Poggi, ingénieur "organisation et méthode» au sein de la direction des Finances départementales et $d u$ Patrimoine du conseil général, et Jean-Louis Champsaur, architecte et président du Conseil d'architecture, d'urbanisme et de l'environnement (CAUE) des Bouches-du-Rhône, forment une cellule opérationnelle qui pilote et 
coordonne le projet depuis sa genèse jusqu'à l'inauguration du nouvel édifice. Ils s'informent sur les réalisations récentes et vont notamment visiter, le 25 août 1988, l'hôtel de département de l'Hérault (fig. 12) récemment achevée ${ }^{30}$.

Figure 12

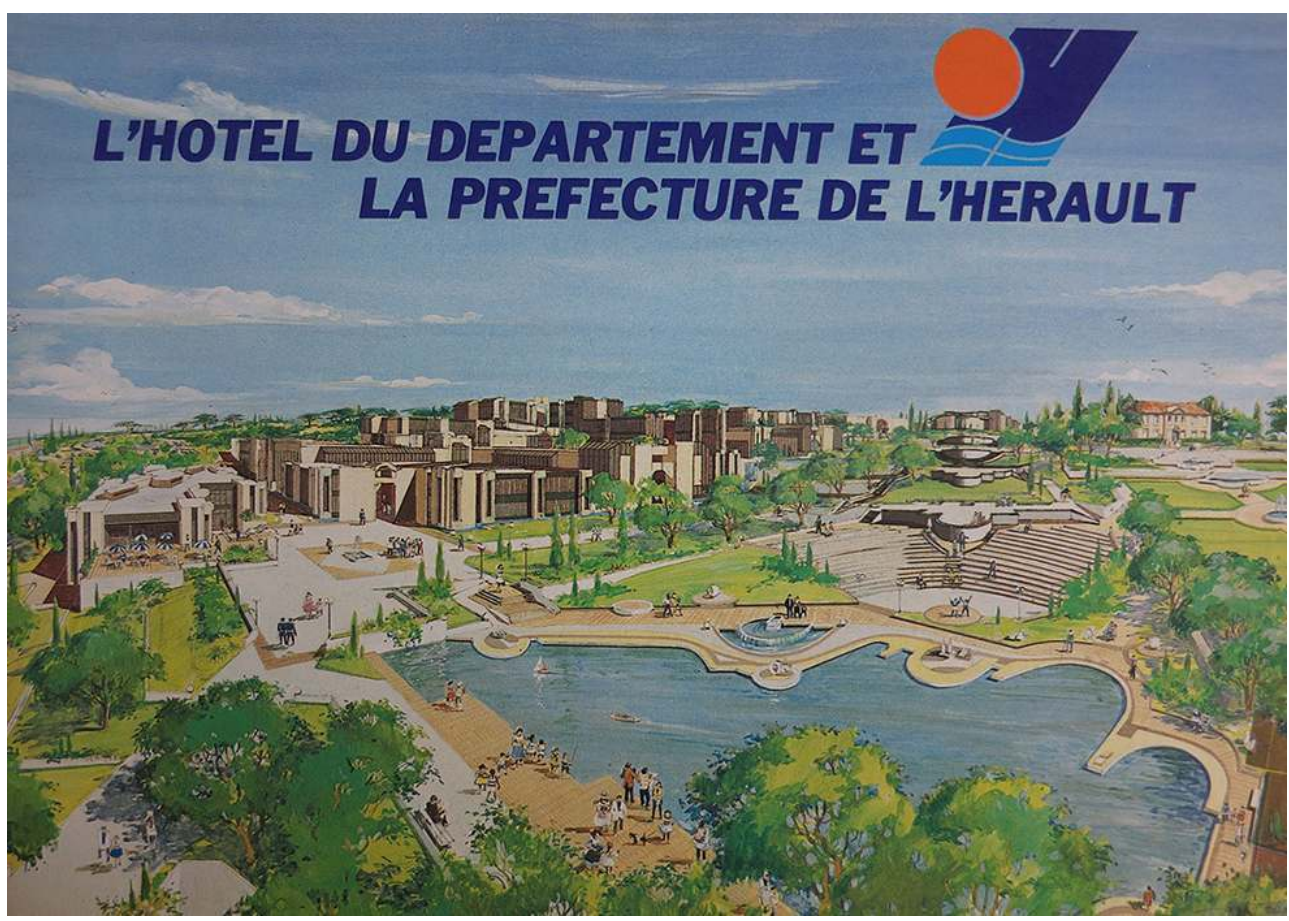

Hôtel de département de l'Hérault, Montpellier (1985-1987, arch. : AUA de Crouzet, Michel, Tourre). Plaquette de présentation de l'hôtel de département de l'Hérault (s.d. circa 1987), (AD BdR, 2233 W 26).

(C) $\mathrm{AD} \mathrm{BdR}$.

Ils s'emploient ensuite à donner une forte visibilité au concours ${ }^{31}$, notamment en formant un jury international à la hauteur des ambitions de la maitrise d'ouvrage (fig. 13). Y siègent, outre le président - Lucien Weygand - et les représentants du conseil départemental, des architectes de différentes nationalités (Anglais, Australiens, Belges, Espagnols, Français et Italiens) reconnus à l'échelle européenne comme Massimiliano Fuksas (né en 1944), Lucien Kroll (né en 1927), John Miller (né en 1930), Manolo NunezYanowsky (né en 1942), Paolo Portoghesi (né en 1931), Fernando Ramos (né en 1942), Rudy Ricciotti (né en 1952), Francis Soler (né en 1949), Peter Wilson (né en 1950), ainsi que des personnalités influentes du monde de l'architecture telles que Patrice Goulet (né en 1941). Ce jury est épaulé par une commission technique dans laquelle Jean-Michel Battesti, qui vient d'achever l'immeuble des Présentines pour le compte du conseil régional, joue un rôle essentiel ${ }^{32}$. 


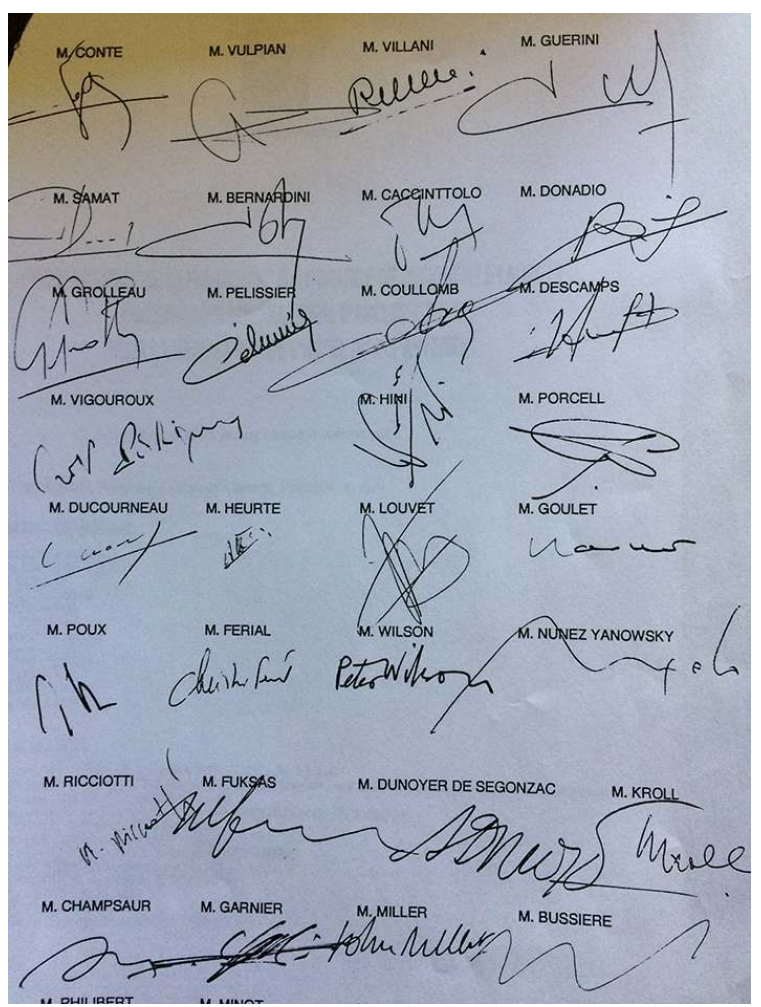

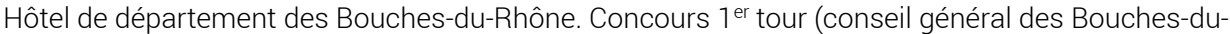
Rhône, 2-3 avril 1990). Extrait du registre de signature des membres du jury (3 avril 1990) (AD BdR, 2338 W 11).

(c) AD BdR.

Sur 145 inscrits au concours ${ }^{33}, 84$ déposent leur projet dans les temps ${ }^{34}$ dont Gérard Grandval (né en 1930), Olivier Dugas (né en 1937), Denis Sloan (né en 1934), Roland Castro (né en 1940), Paul Chemetov (né en 1928) et Borja Huidobro (né en 1936), Claude Vasconi (1940-2009) qui achevait tout juste l'hôtel de département du Bas-Rhin (1986-1990) (fig. 14), Alain Sarfati (né en 1937), Jean-Pierre Buffi (né en 1937) qui avait réalisé le bâtiment du conseil général de Martinique (1975-1978), Françoise-Hélène Jourda (1955-2015) et Gilles Perraudin (né en 1949), Claude Parent, Alexis Josic (1921-2011), Daniel Badani (1914-2006), Jean-Paul Viguier (né en 1946) pour ne citer que quelques représentants de la scène française. 


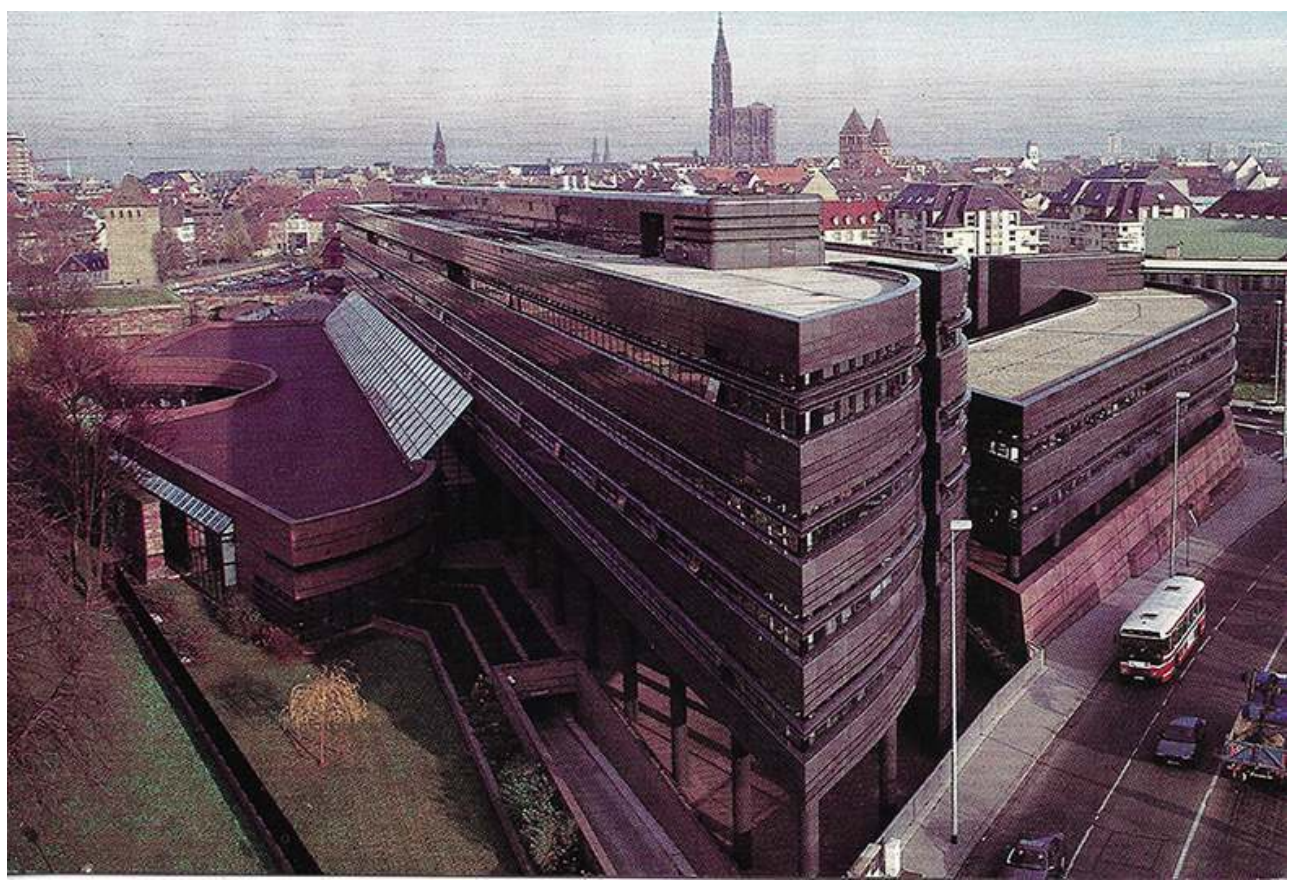

Hôtel de département du Bas-Rhin, Strasbourg (1986-1990, arch. : Claude Vasconi). Carte postale (s.d.), collection de l'auteur.

13 Finalement, assez peu d'agence locales prennent part au concours en leur nom propre (Urbain-Lamasse, CCD Architecture, Savignat-Chancel, Gros, Pons-Biaggi-Maurin, Maupin-Tarrazi, Eisenlhor-Siame), peut-être conscientes que leurs chances sont faibles compte tenu des ambitions clairement affichées par la maîtrise d'ouvrage. Des architectes britanniques tels que William Alsop (né en 1947), Norman Foster (né en 1935) ou encore l'agence Greenhill-Jenner-Richard, mais aussi italiens (Vittorio Mazzucconi, Rinaldo Olivieri, Attilio Marchesi) et roumains (Andras Peres, Laura Manca, Cosma Jurov) figurent parmi les dix-huit candidats étrangers. La première réunion du jury intervient les 2 et 3 avril $1990^{35}: 46$ projets sont éliminés par un premier vote (à main levée); un deuxième permet de ne retenir que 23 projets (les candidats obtenant au moins 5 voix); puis, afin de n'en garder que 15 au soir de la première journée de délibération, le président du jury procède à un troisième tour de scrutin. Le lendemain, un vote préférentiel à bulletin secret départage les candidats encore en lice. Après levée de l'anonymat, les noms des cinq finalistes (fig. $15,16,17,18,19)$ sont révélés ${ }^{36}$ : William Alsop (avec John Lyall, Londres, Royaume-Uni), Norman Foster (Londres, Royaume-Uni), Françoise-Hélène Jourda et Gilles Perraudin (Lyon, France), Pascal Urbain (né en 1952, avec Lamasse, Marseille, France) et enfin l'équipe formée par Fernando Urquijo, Gino Valle et Giorgio Macola ${ }^{37}$ (équipe italiano-uruguayenne basée à Paris, France); une seule équipe est marseillaise (Urbain et Lamasse), deux bénéficient d'une reconnaissance internationale (Foster; Urquijo, Valle et Macola) et deux sont de jeunes agences, l'une française (Jourda et Perraudin), l'autre britannique (Alsop). 


\section{Figure 15}

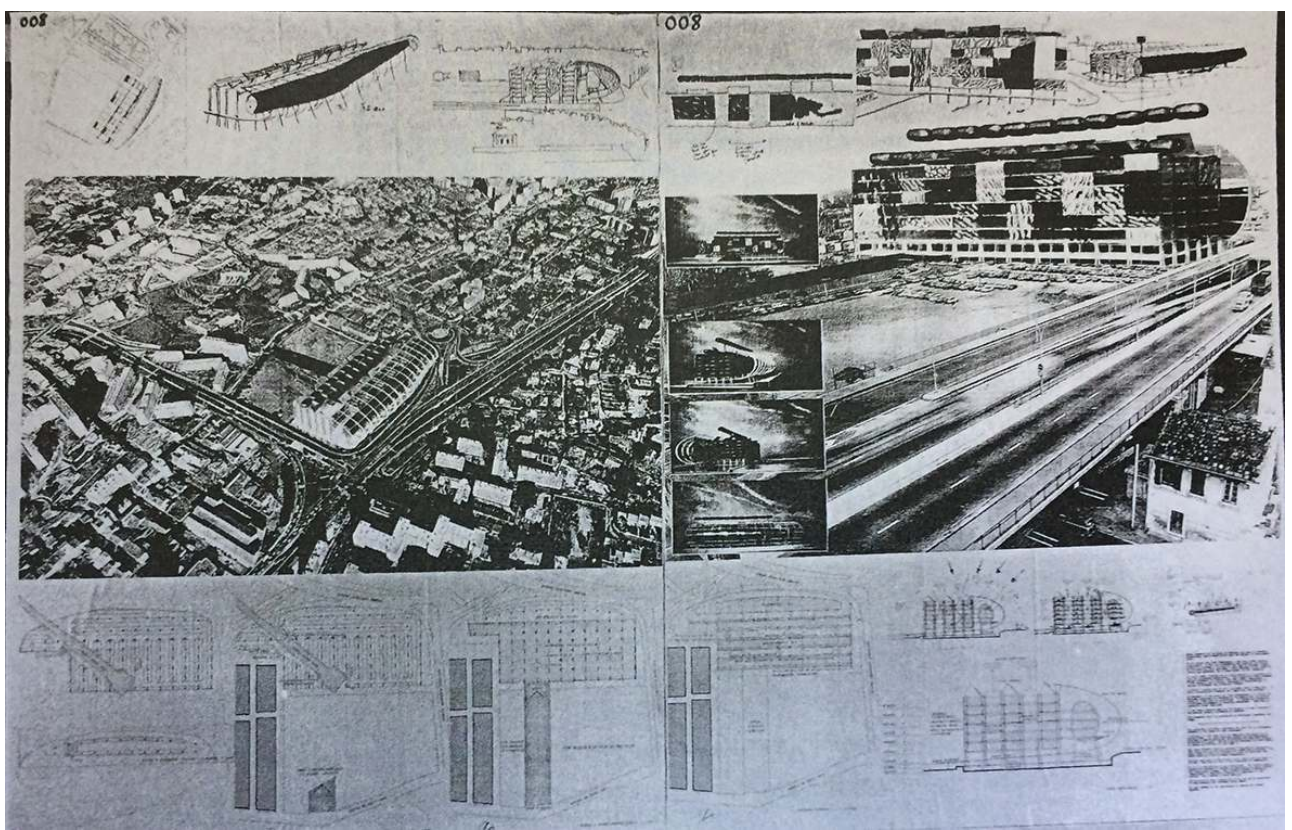

Hôtel de département des Bouches-du-Rhône. Concours (conseil général des Bouches-du-Rhône, 1990). Planche du projet de William Alsop et John Lyatt retenu à l'issue du $7^{\text {er }}$ tour du concours (2-3 avril 1990) (AD BdR, 2333 W 16).

(c) $\mathrm{AD} B d R$.

\section{Figure 16}

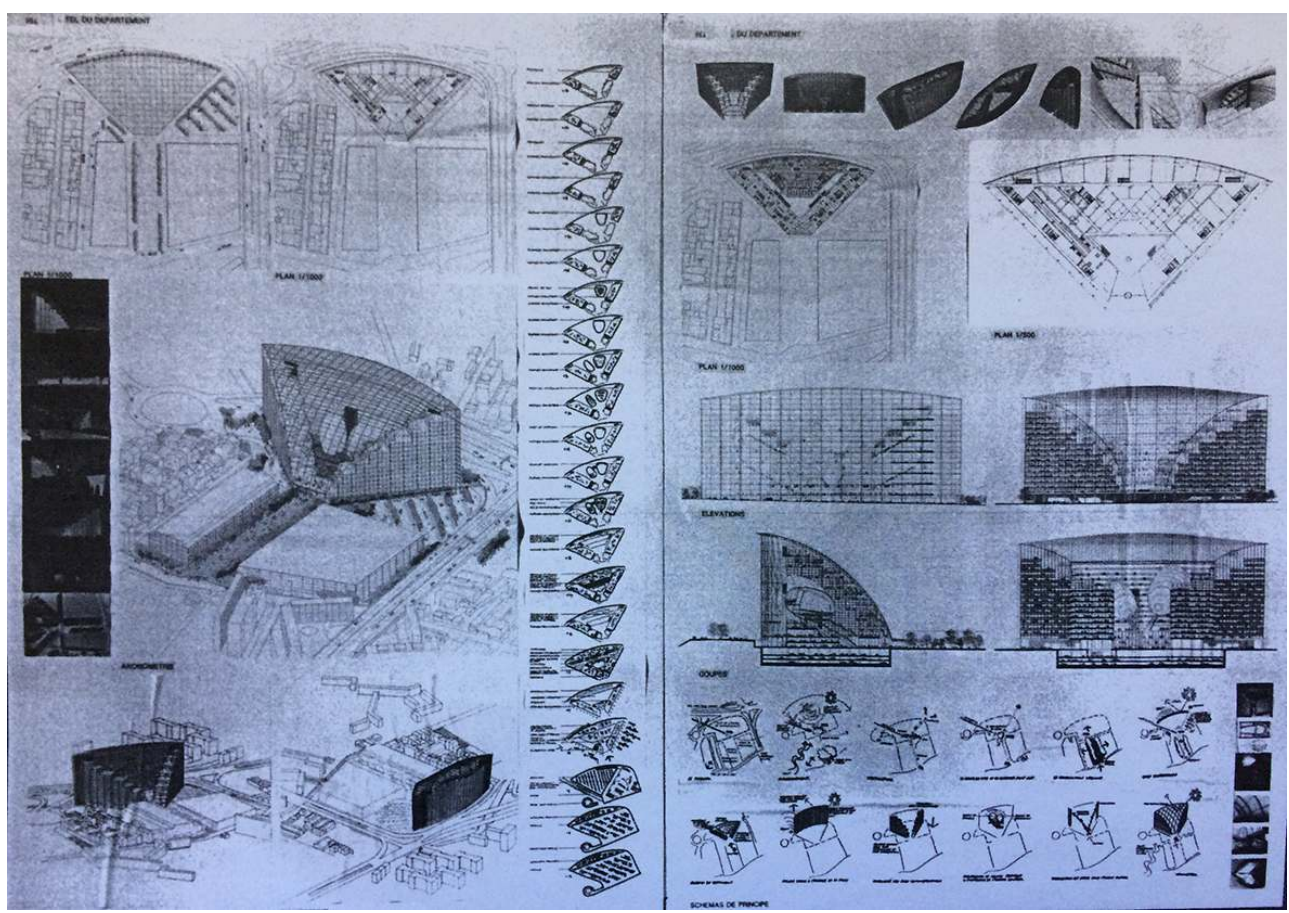

Hôtel de département des Bouches-du-Rhône. Concours (conseil général des Bouches-du-Rhône, 1990). Planche du projet de Norman Foster retenu à l'issue du $1^{\text {er }}$ tour du concours (2-3 avril 1990) (AD BdR, 2333 W 16).

(C) $\mathrm{AD} B d R$. 
Figure 17

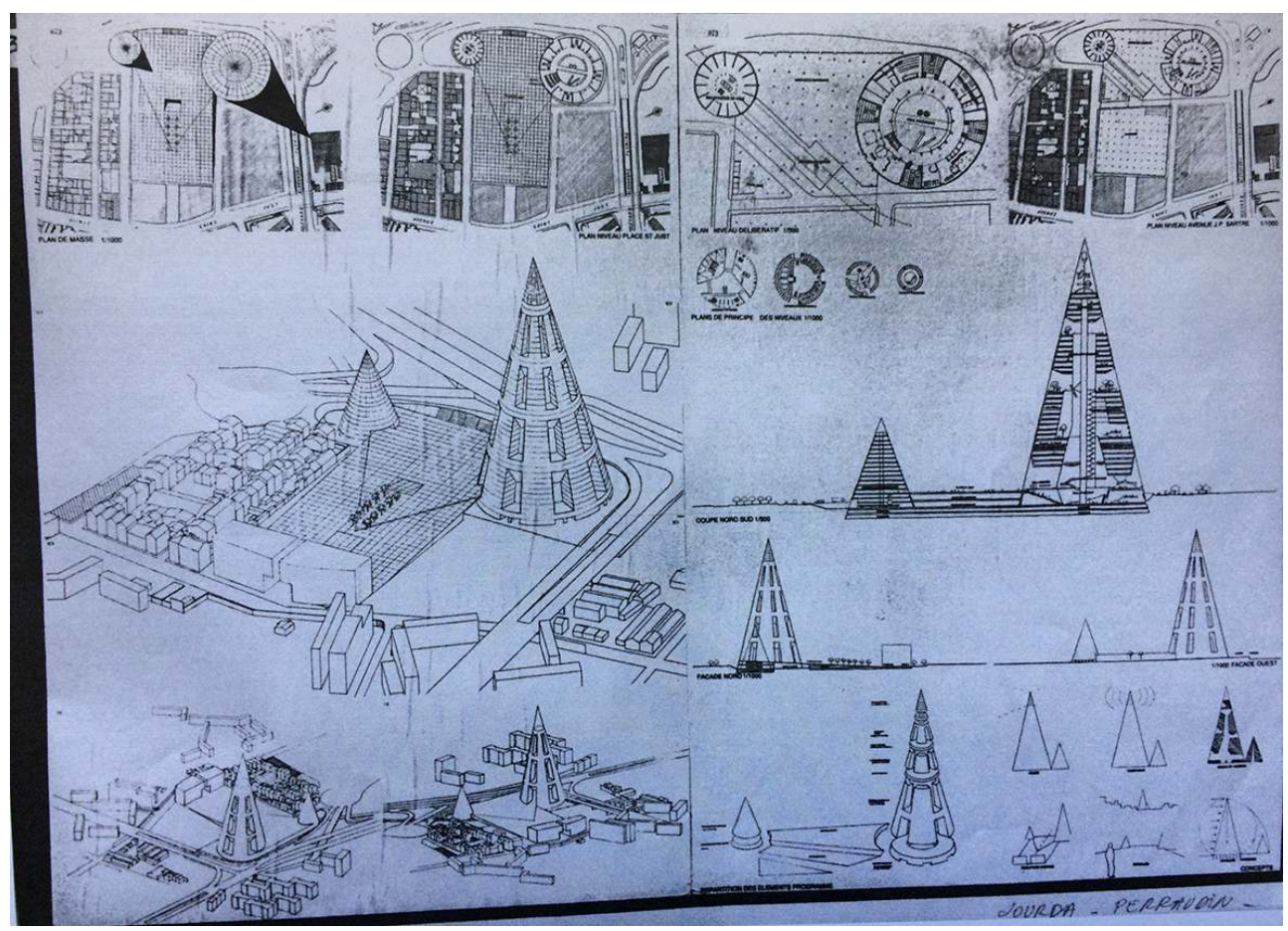

Hôtel de département des Bouches-du-Rhône. Concours (conseil général des Bouches-du-Rhône, 1990). Planche du projet de Jourda et Perraudin retenu à l'issue du $7^{\text {er }}$ tour du concours (2-3 avril 1990) (AD BdR, 2333 W 16).

(C) $\mathrm{AD} \mathrm{BdR}$. 
Figure 18

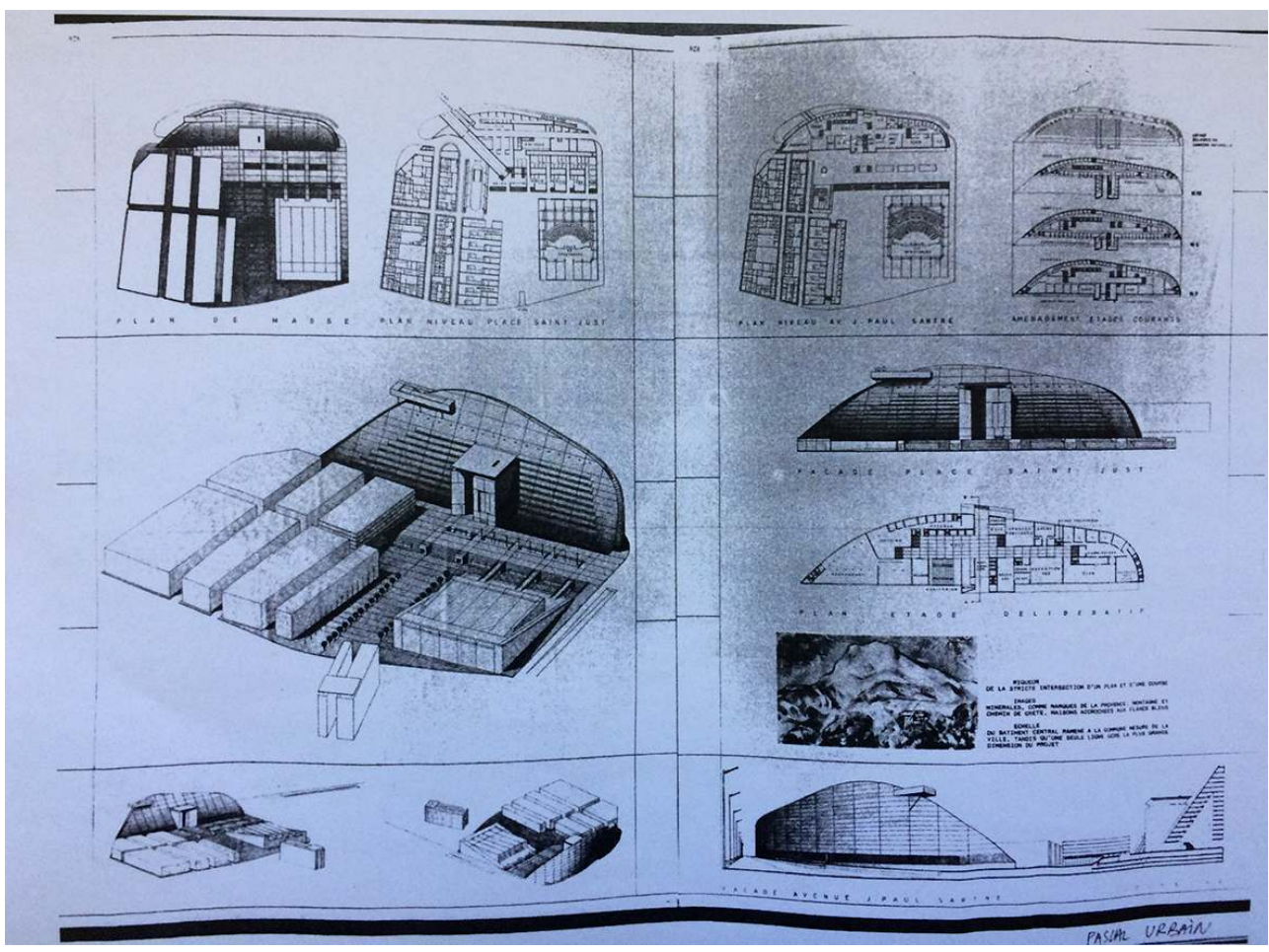

Hôtel de département des Bouches-du-Rhône. Concours (conseil général des Bouches-du-Rhône, 1990). Planche du projet d'Urbain et Lamasse retenu à l'issue du $7^{\text {er }}$ tour du concours (2-3 avril 1990) (AD BdR, 2333 W 16).

(C) $\mathrm{AD} B d R$. 
Figure 19

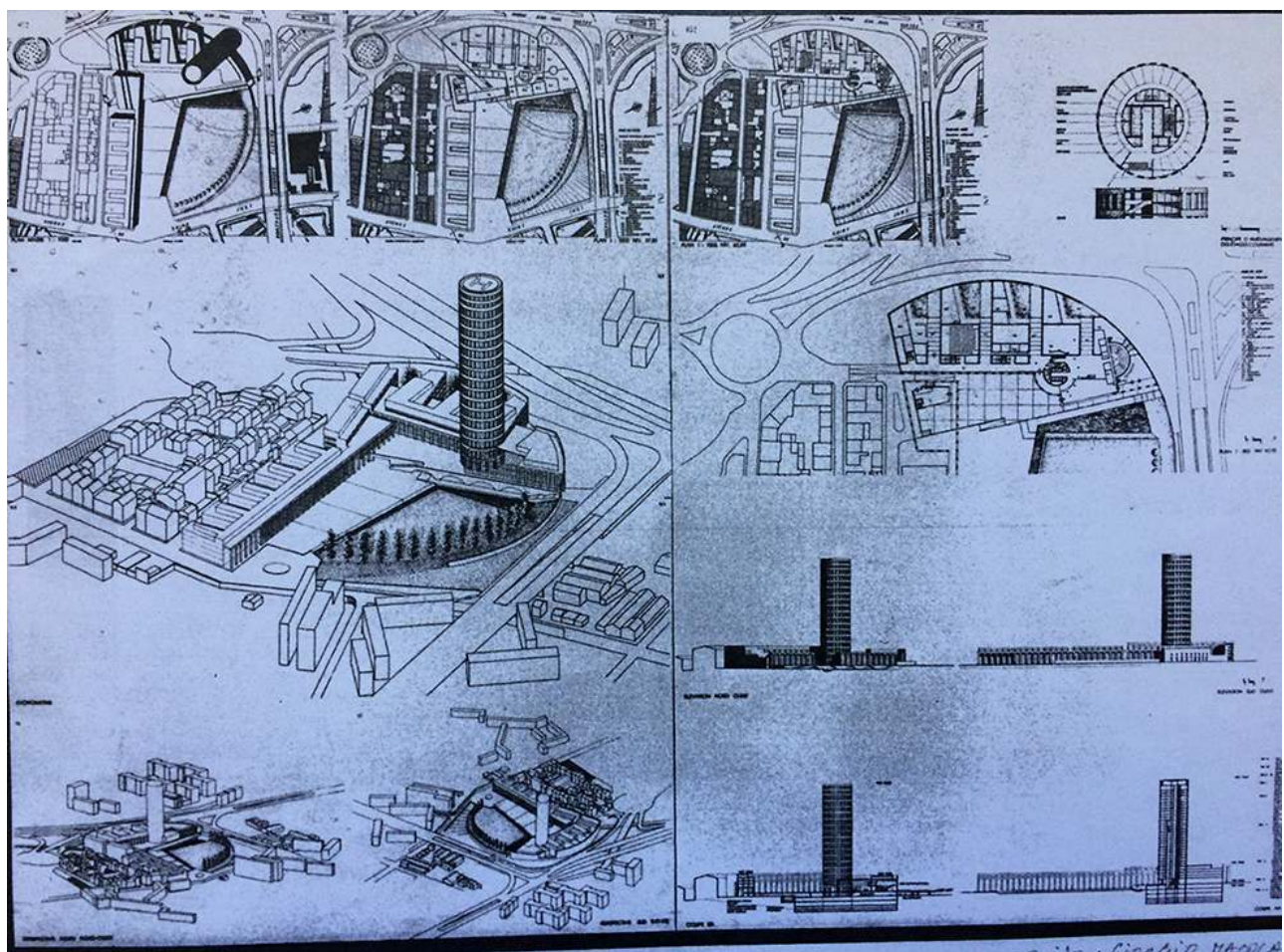

Hôtel de département des Bouches-du-Rhône. Concours (conseil général des Bouches-du-Rhône, 1990). Planche du projet de Urquijo-Valle-Macola retenu à l'issue du $7^{\text {er }}$ tour du concours (2-3 avril 1990) (AD BdR, 2333 W 16).

(C) $A D B d R$.

Tous doivent fournir un APS simplifié dans la perspective du second tour du concours. Jourda et Perraudin baptisent le leur d'un axiome témoignant d'une fine compréhension des enjeux du concours - "fédérer l'espace urbain avec un monument alliant la modernité d'une tour à la pérennité d'une pyramide au service de la collectivité38 ${ }^{38}$ - mais qui ne suffit pas à convaincre le jury. À l'issue de cette nouvelle consultation ( 7 et 8 juin 1990), à la surprise générale, le jury ne désigne pas de lauréat mais retient les projets de William Alsop et de Norman Foster, en leur demandant « un complément d'information sur les aspects techniques et financiers de leurs projets, dans un délai de 20 jours ${ }^{39}$ \%. 


\section{Figure 20}

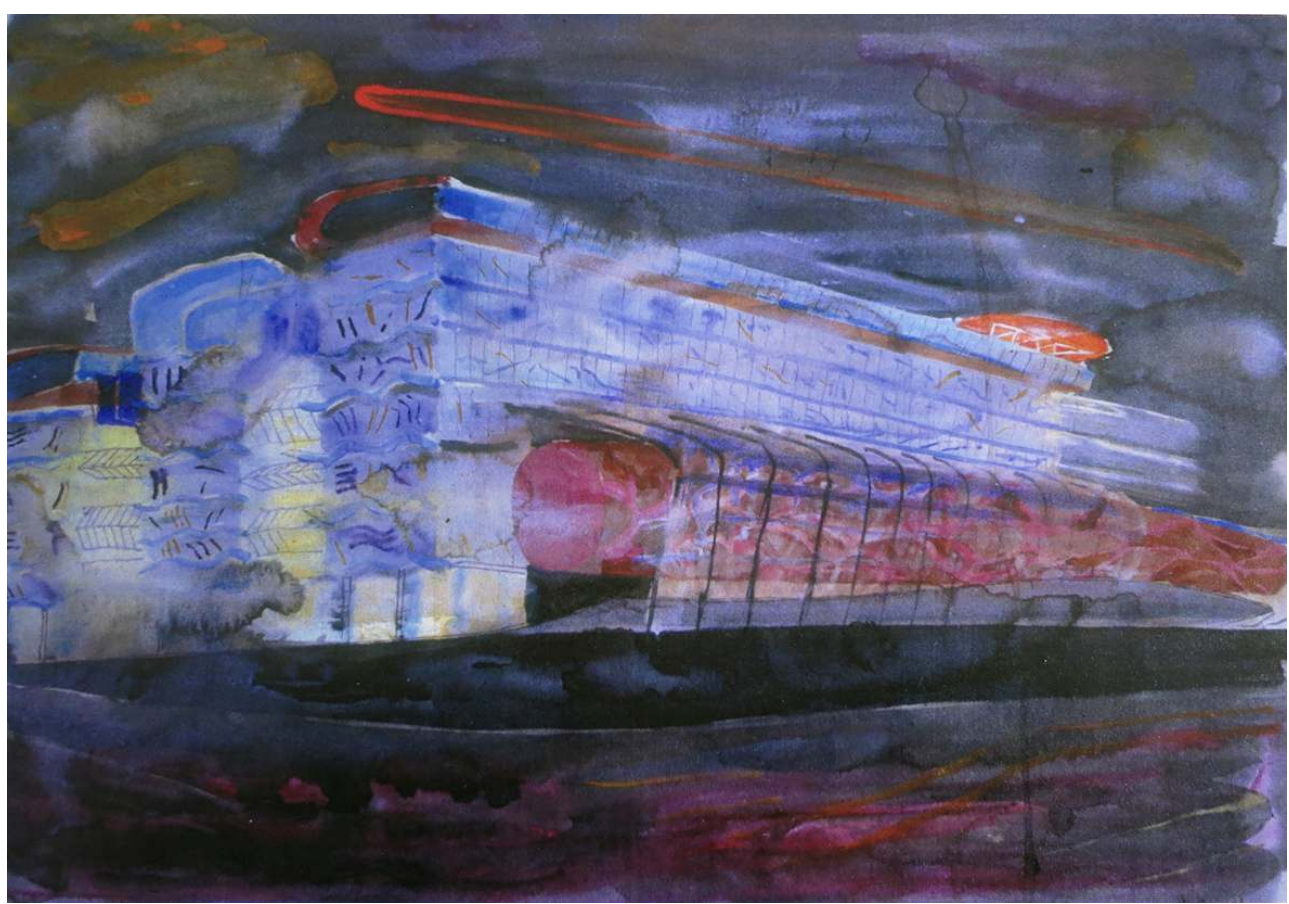

Hôtel de département des Bouches-du-Rhône. Concours (conseil général des Bouches-du-Rhône, 1990). Recueil fourni par William Alsop et John Lyall pour la $2^{\mathrm{e}}$ manche du $2^{\mathrm{e}}$ tour du concours (juillet 1990) (AD BdR, 2133 W 3).

(c) AD BdR.

\section{Figure 21}

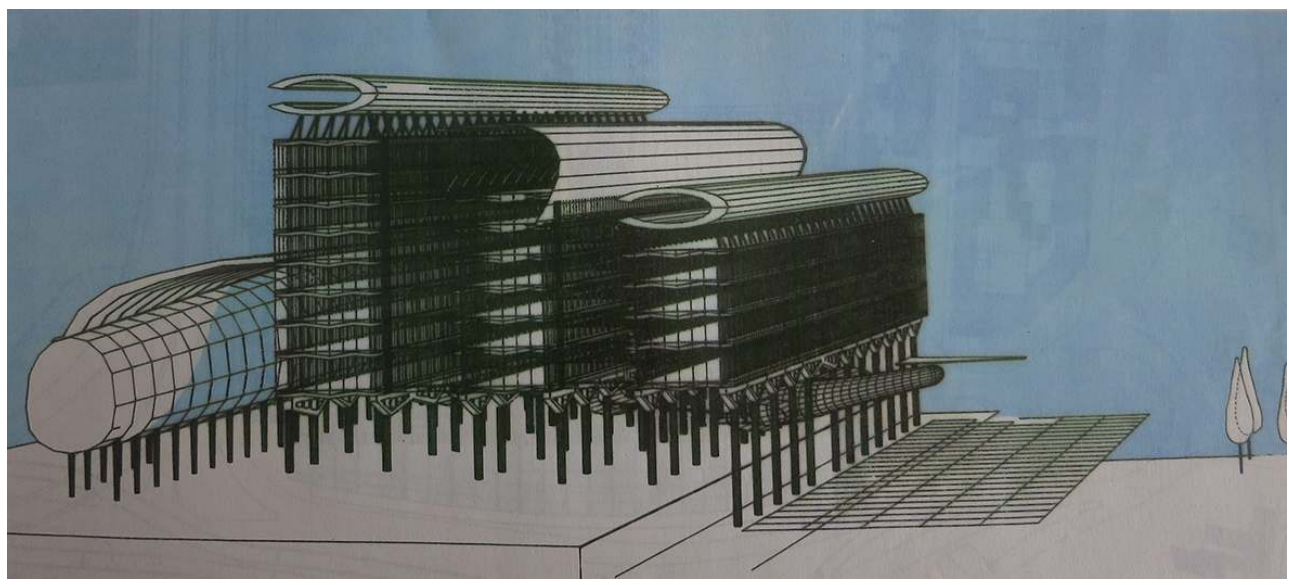

Hôtel de département des Bouches-du-Rhône. Concours (conseil général des Bouches-du-Rhône, 1990). Recueil fourni par William Alsop et John Lyall pour la $2^{\mathrm{e}}$ manche du $2^{\mathrm{e}}$ tour du concours (juillet 1990) (AD BdR, 2133 W 3).

(c) $\mathrm{AD} \mathrm{BdR}$. 
Figure 22

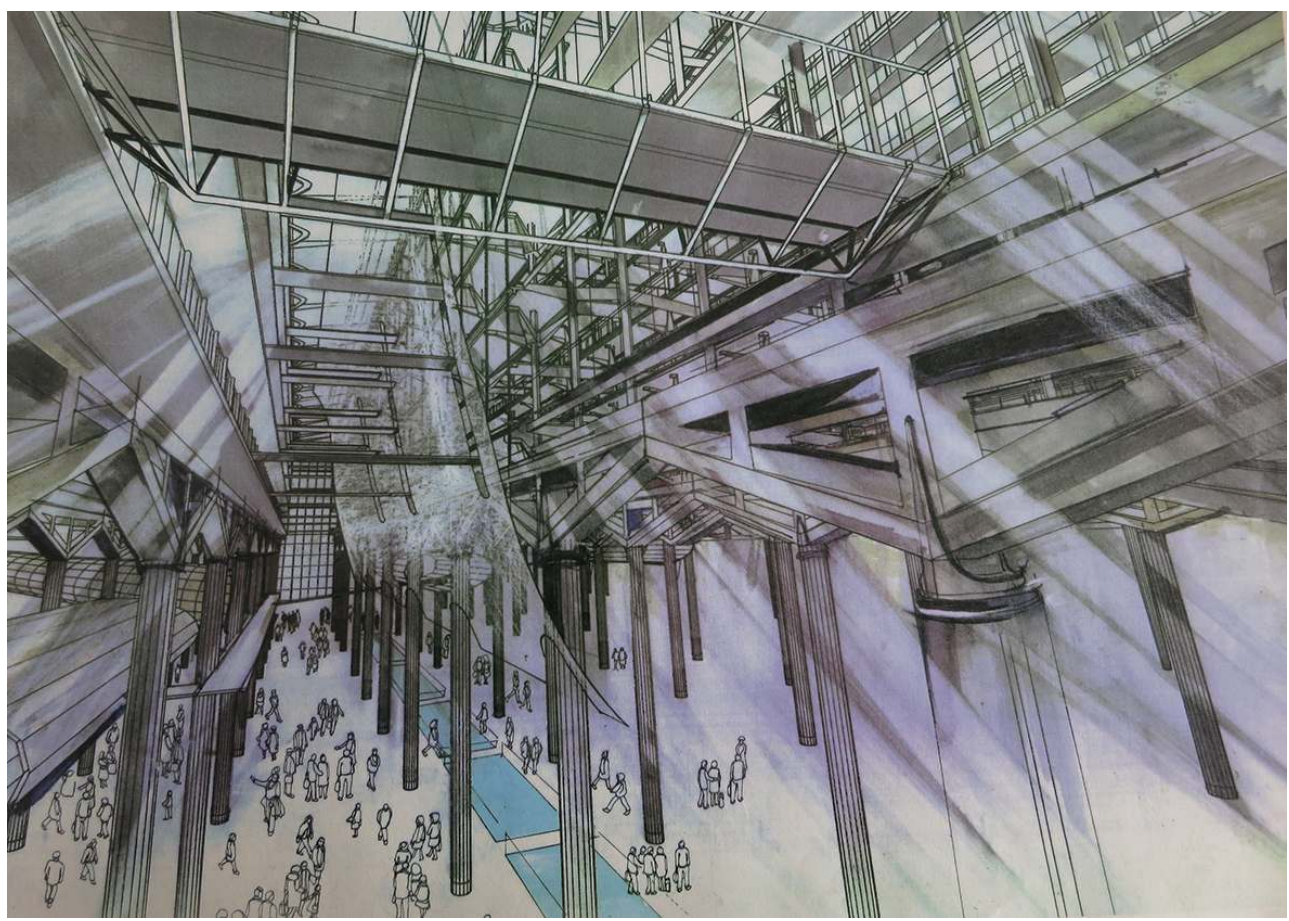

Hôtel de département des Bouches-du-Rhône. Concours (conseil général des Bouches-du-Rhône, 1990). Recueil fourni par William Alsop et John Lyall pour la $2^{\mathrm{e}}$ manche du $2^{\mathrm{e}}$ tour du concours (juillet 1990) (AD BdR, 2133 W 3).

(c) $\mathrm{AD} \mathrm{BdR}$.

Très consciencieusement, William Alsop fournit un recueil (fig. 20, 21, 22) - presque un livre - comprenant textes explicatifs, gouaches et perspectives, plans d'architecte et plans techniques tandis que Norman Foster transmet quelques images de synthèse (fig. 23, fig. 24). Sur cette base, les deux candidats sont auditionnés par la commission technique (5 juillet 1990), à la suite de quoi William Alsop est déclaré lauréat. 


\section{Figure 23}

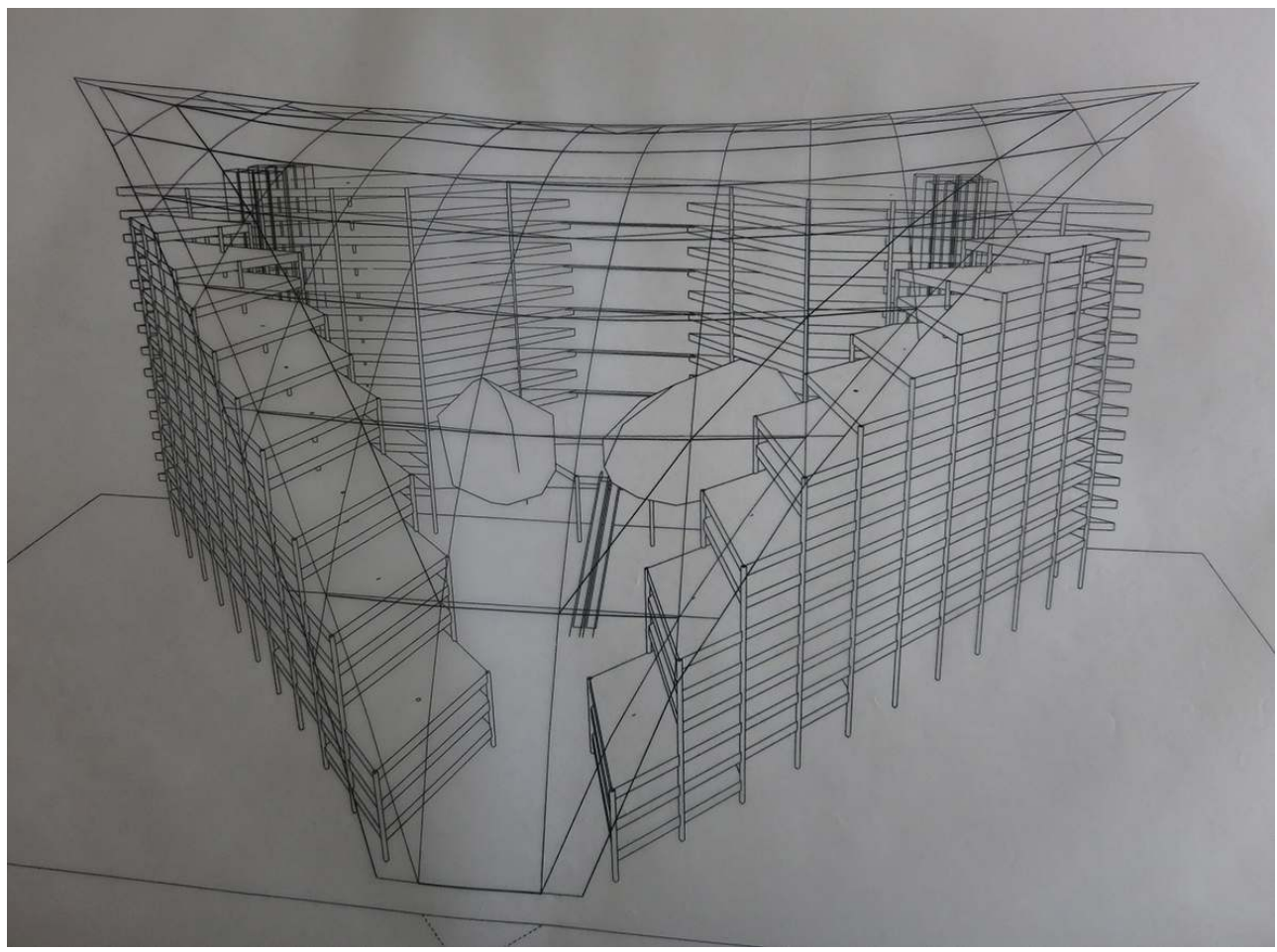

Hôtel de département des Bouches-du-Rhône. Concours (conseil général des Bouches-du-Rhône, 1990). Planche extraite de l'album fourni par Norman Foster pour la $2^{\mathrm{e}}$ manche du $2^{\mathrm{e}}$ tour du concours (juillet 1990) (AD BdR, 2133 W 4).

(c) $\mathrm{AD} \mathrm{BdR}$. 
Figure 24

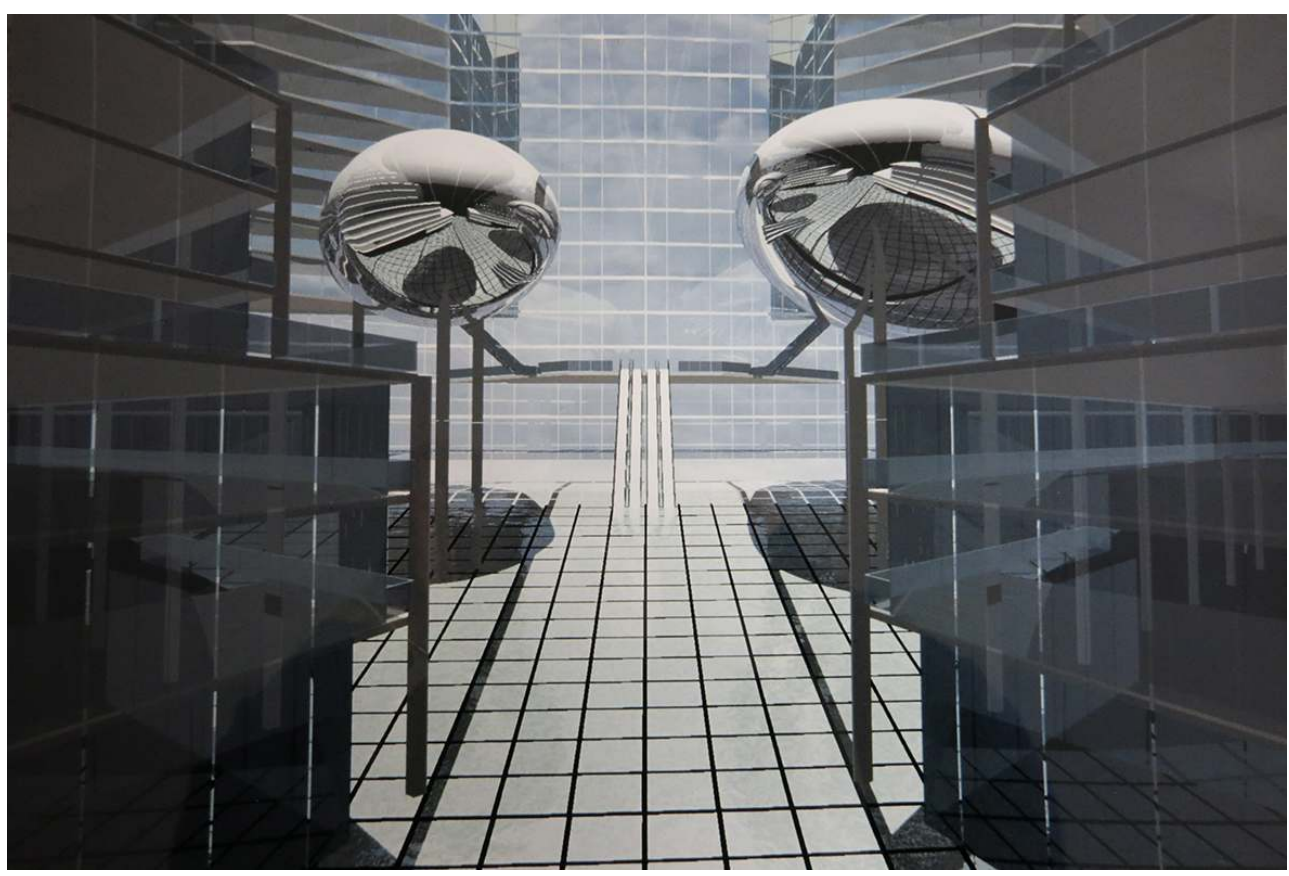

Hôtel de département des Bouches-du-Rhône. Concours (conseil général des Bouches-du-Rhône, 1990). Planche extraite de l'album fourni par Norman Foster pour la $2^{\mathrm{e}}$ manche du $2^{\mathrm{e}}$ tour du concours (juillet 1990) (AD BdR, 2133 W 4).

(c) AD BdR.

\section{L'architecture, objet et outil de reconquête}

16 Au-delà des processus de sélection qui sont déjà très révélateurs de la façon dont les collectivités endossent leur rôle de maîtres d'ouvrage, la mise en regard de l'hôtel de région de PACA et de l'hôtel du département des Bouches-du-Rhône montre combien, à la mi-temps des années 1980, à partir d'un même type de programme - un édifice public, lieu de décision, de gestion et de représentation d'une collectivité territoriale l'architecture devient à la fois un objet et un outil de reconquête. La situation urbaine des bâtiments - le centre-ville pour l'hôtel de région, le quartier de Saint-Just en lisière de la ville dense pour l'hôtel de département - explique en partie, mais en partie seulement, cette nouvelle dynamique.

\section{L'hôtel de région, un monument en situation urbaine}

17 Les locaux du Grand Pavois ${ }^{40}$, occupés par les services de l'établissement public régional depuis sa création, sont trop exigus pour accueillir les fonctionnaires et les élus du conseil régional instauré par la loi de décentralisation du 2 mars 1982. Après avoir envisagé d'installer l'hôtel de région dans la partie basse du fort Saint-Nicolas (1982-février 1983), puis dans une bastide située sur le boulevard Michelet (juin 1983) ou d'agrandir les locaux du Grand Pavois ${ }^{41}$ (1984), il est finalement décidé de construire un nouveau bâtiment au cœur de la cité phocéenne, sur la place de la Porte-d'Aix dont la morphologie avait été profondément bouleversée en 1971 par la percée de l'autoroute Nord ${ }^{42}$. 
L'implantation de l'hôtel de région participe d'une opération de requalification urbaine de plus grande ampleur, initiée en 1975 dans le cadre d'une zone d'aménagement concerté (ZAC), la ZAC Sainte-Barbe (1975-1983). Censée participer de la résorption de l'habitat insalubre ${ }^{43}$, cette ZAC pilotée par l'Agence d'urbanisme de l'agglomération marseillaise (AgAM, créée en 1969) entraîne l'arasement de la Butte-aux-Carmes, la destruction des anciennes prisons et caserne de gendarmerie des Présentines ${ }^{44}$ (1820-1823, arch.: Michel-Robert Penchaud) ainsi que la disparition d'une vingtaine de rues au profit d'un ensemble de logements et de bureaux, en lieu et place desquels s'implantera l'hôtel de région (fig. 25).

Figure 25

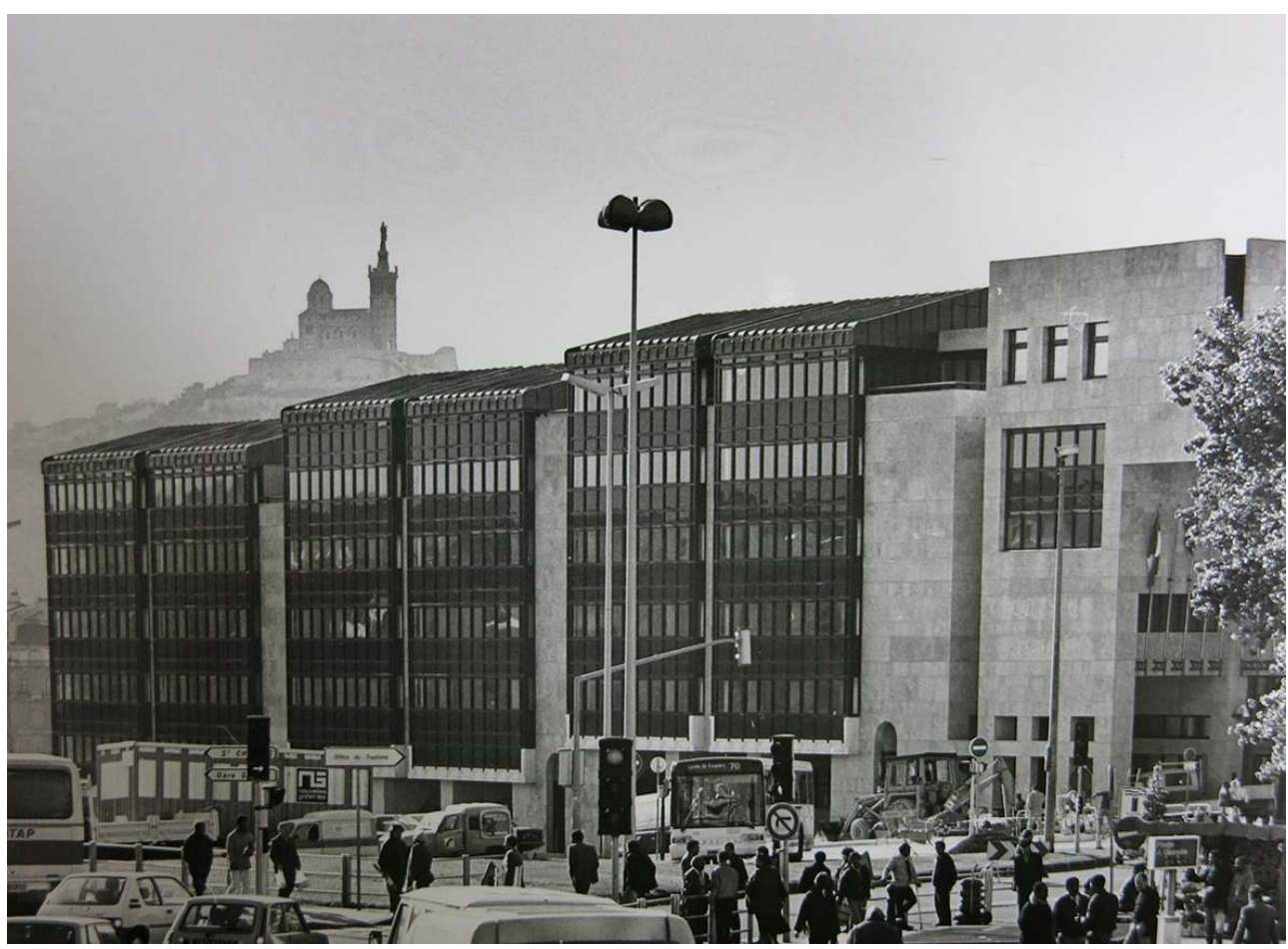

Hôtel de région de PACA. Immeuble des Présentines (1984-1987, arch. : Jean-Michel Battesti). Photographie depuis la Porte d'Aix (s.d. circa 1987) (ARPACA 181/02).

(c) AD ARPACA.

Dans cette opération, la rue Sainte-Barbe voit son tracé modifié pour constituer une " délimitation urbaine franche $»^{45}$ articulant le site de la Porte-d'Aix avec le quartier de la Bourse. Lorsqu'il aborde le concours, Jean-Michel Battesti est conscient de l'importance de cette donnée. A posteriori, il confirmera que « c'est un retour à l'ordre urbain, dans une quête d'urbanité, qui a informé le tracé d'implantation de l'immeuble des Présentines et notamment l'imposition d'une galerie piétonne publique couverte à rez-de-chaussée ${ }^{46} \mathrm{le}$ long de la rue Sainte-Barbe. Cette galerie publique, qui lui est inspirée par les immeubles du Vieux-Port de Fernand Pouillon, ne présente, malgré sa déclivité, ni marche ni degré. L'immeuble, en L, forme un retour du côté de la place Jules-Guesde, où sa façade en pierre calcaire dialogue avec le vestige d'un aqueduc romain ${ }^{47}$. Le volume d'angle, traité en creux, constitue un pivot d'articulation entre la place, l'entrée de l'hôtel de région et la galerie piétonne (fig. 26). L'immeuble présente deux niveaux de sous-sols destinés au stationnement (100 places environ) ainsi que six niveaux (rez-de-chaussée et 5 étages) de bureaux (194 bureaux, 9 salles de réunion) où travaillent environ 350 agents tandis que le 
rez-de-chaussée est dévolu à des espaces collectifs ${ }^{48}$. Les séquences de sa façade (verrières en verre fumé et revêtement en pierre calcaire), tout comme celles de sa couverture (« boîtes » revêtues de bandes de cuivre), accompagnent la déclivité de la rue (4 mètres) dans une volonté revendiquée d'insertion urbaine.

Figure 26

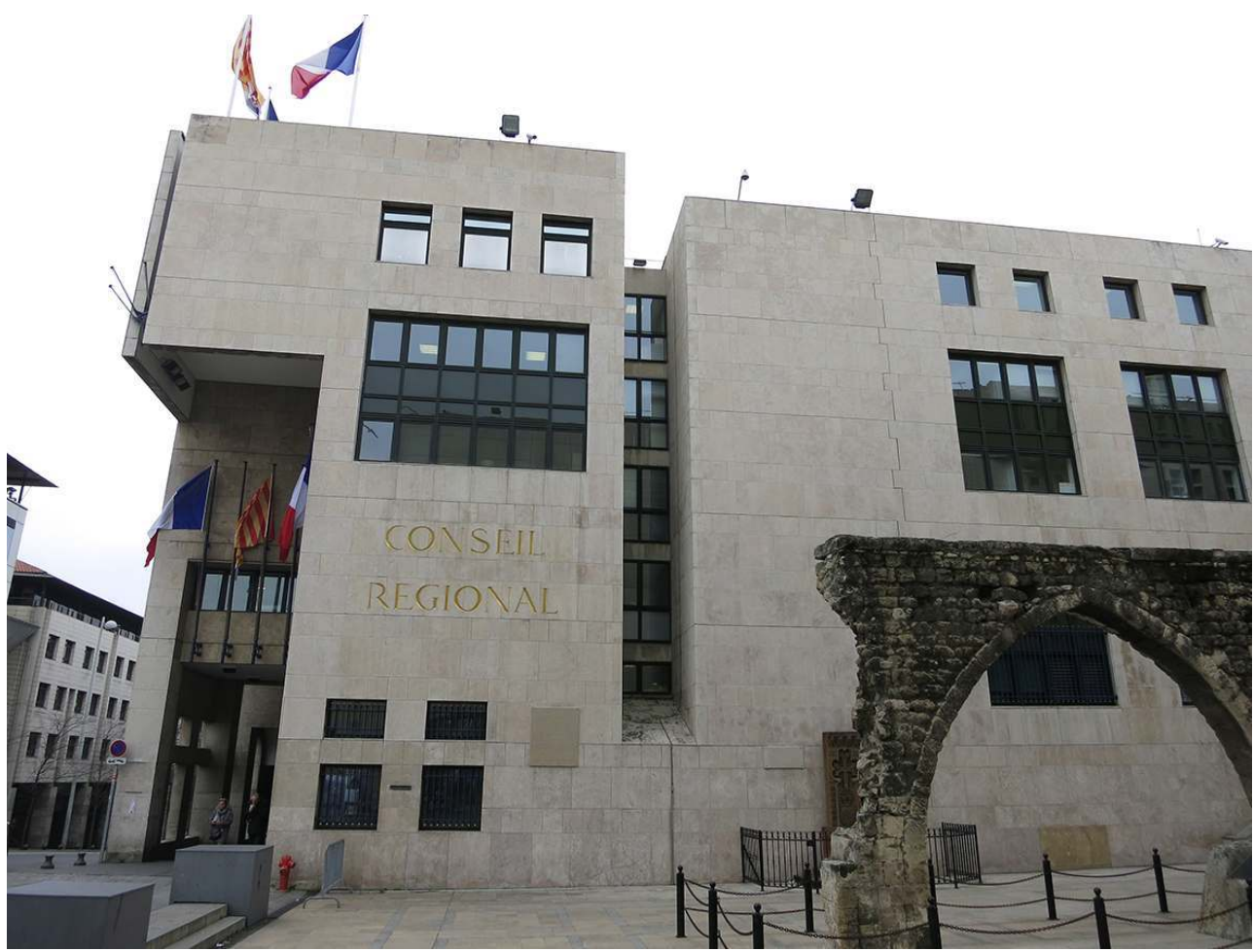

Hôtel de région de PACA. Immeuble des Présentines (1984-1987, arch. : Jean-Michel Battesti). Vue actuelle.

Phot. Éléonore Marantz, 2015. @ Éléonore Marantz.

Ce parti est prolongé par le «bloc plénier » de Claude Parent, qui s'articule, voire englobe, le bâtiment de Jean-Michel Battesti, et s'emploie, lui aussi, à permettre des connexions avec les différentes composantes du site (fig. 27). 


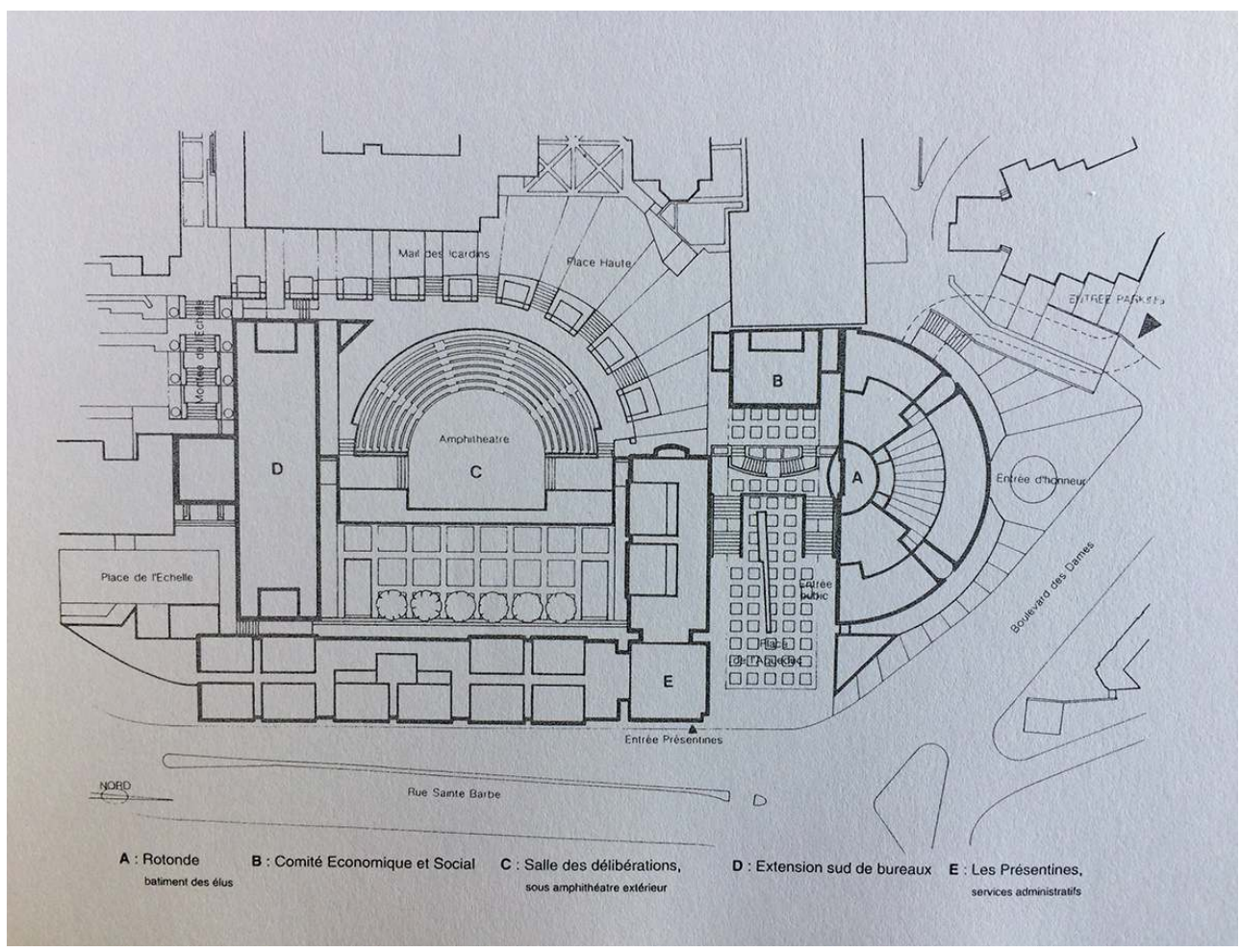

Hôtel de région de PACA (1984-1986, arch. : Jean-Michel Battesti ; 1987-1991, arch. : Claude Parent, Christian Biaggi, Bruno Maurin). Plan d'ensemble (s.d. 1991), (ARPACA 4445 W 3).

(C) AD ARPACA.

21 Claude Parent qualifie son bâtiment de "sertissure architecturale dans l'existant", soulignant la présence d'un cheminement qui le traverse de part en part grâce à un jeu de terrasses et d'escaliers extérieurs. Les nouvelles constructions délimitent en outre une cour d'honneur ainsi qu'un amphithéâtre en plein-air - ou place haute - se déployant audessus de la nouvelle salle de l'Assemblée régionale, face aux immeubles de logements de la Butte. À l'intérieur, un « déambulatoire » relie la rotonde (dans laquelle se trouvent un vaste vestibule, des salles de réunion et les bureaux de la présidence, de son cabinet et des élus - environ 80 -) avec le salon d'honneur, la salle à manger des élus, la salle des délibérations (400 places dont 192 pour les élus) et l'immeuble du Conseil économique et social. Le traitement architectural se veut « discret » et " classique ", notamment grâce à l'emploi du béton à l'extérieur comme à l'intérieur ${ }^{49}$. La seule entorse à cette relative retenue est l'atrium semi-circulaire, immense espace libre sous verrière, distribué par un système de rampes (pente à $5 \%$ ) - un lointain souvenir de la fonction oblique chère à Claude Parent - permettant de passer d'un étage à l'autre sans jamais emprunter une seule marche d'escalier ${ }^{50}$. Le bâtiment (fig. 28, 29, 30, 31, 32) est inauguré le 19 décembre 1991 par Jean-Claude Gaudin (président du conseil régional), en présence de Robert Vigouroux (maire de Marseille), Lucien Weygand (président du conseil général) et Claude Bussière (préfet). 


\section{Figure 28}

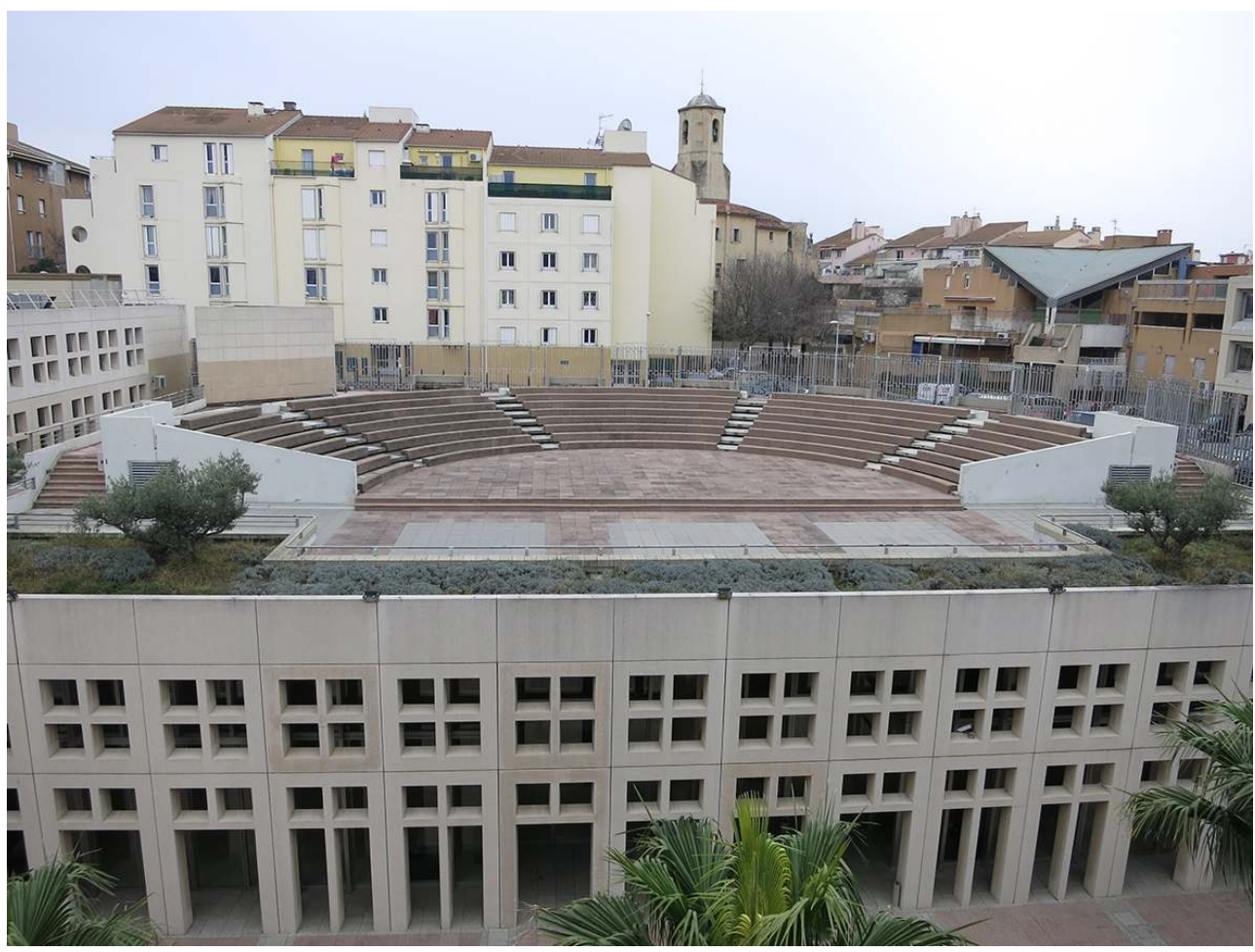

Hôtel de région de PACA. Bloc Plénier (1987-1991, arch. : Claude Parent, Christian Biaggi, Bruno Maurin). Vue actuelle.

Phot. Éléonore Marantz, 2015. @ Éléonore Marantz. 


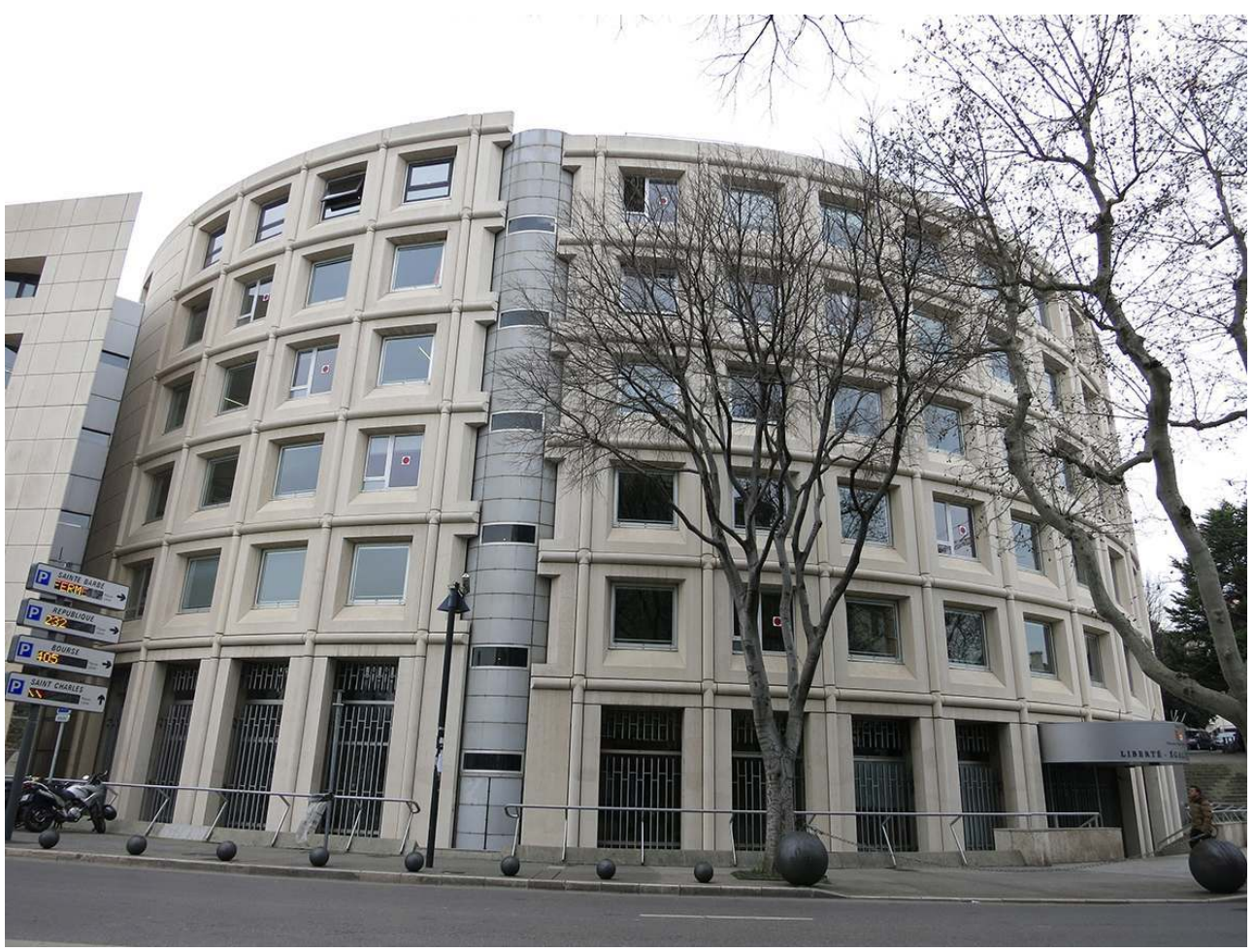

Hôtel de région de PACA. Bloc Plénier (1987-1991, arch. : Claude Parent, Christian Biaggi, Bruno Maurin). Vue actuelle.

Phot. Éléonore Marantz, 2015. @ Éléonore Marantz. 


\section{Figure 30}

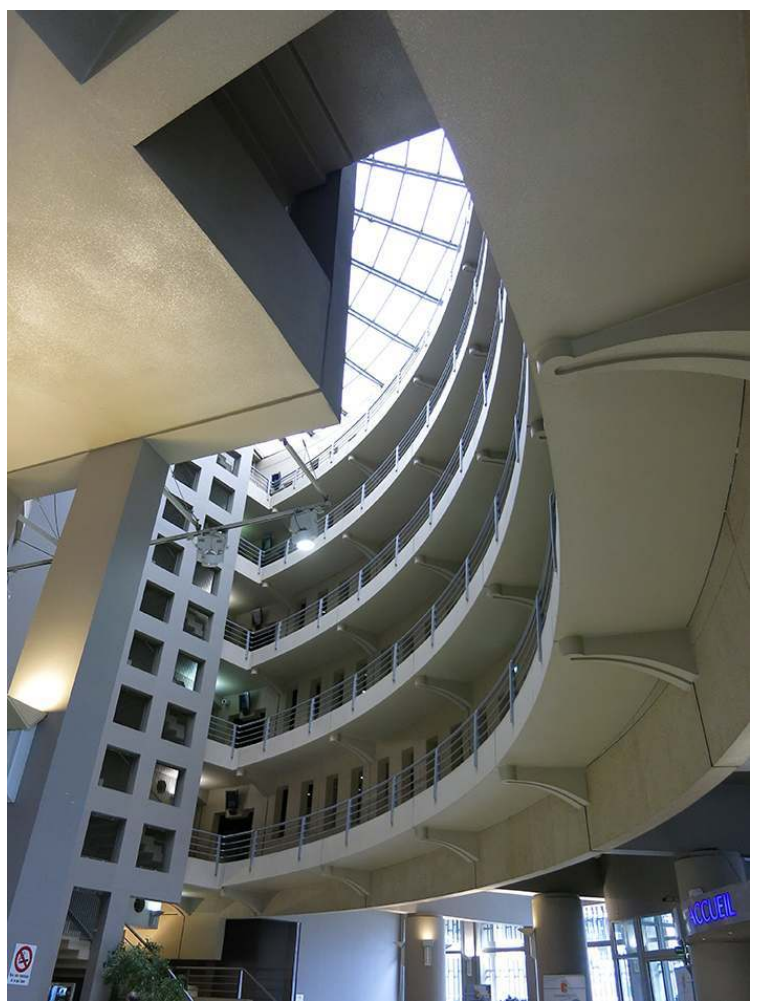

Hôtel de région de PACA. Bloc Plénier (1987-1991, arch. : Claude Parent, Christian Biaggi, Bruno Maurin). Vue actuelle.

Phot. Éléonore Marantz, 2015. () Éléonore Marantz. 
Figure 31

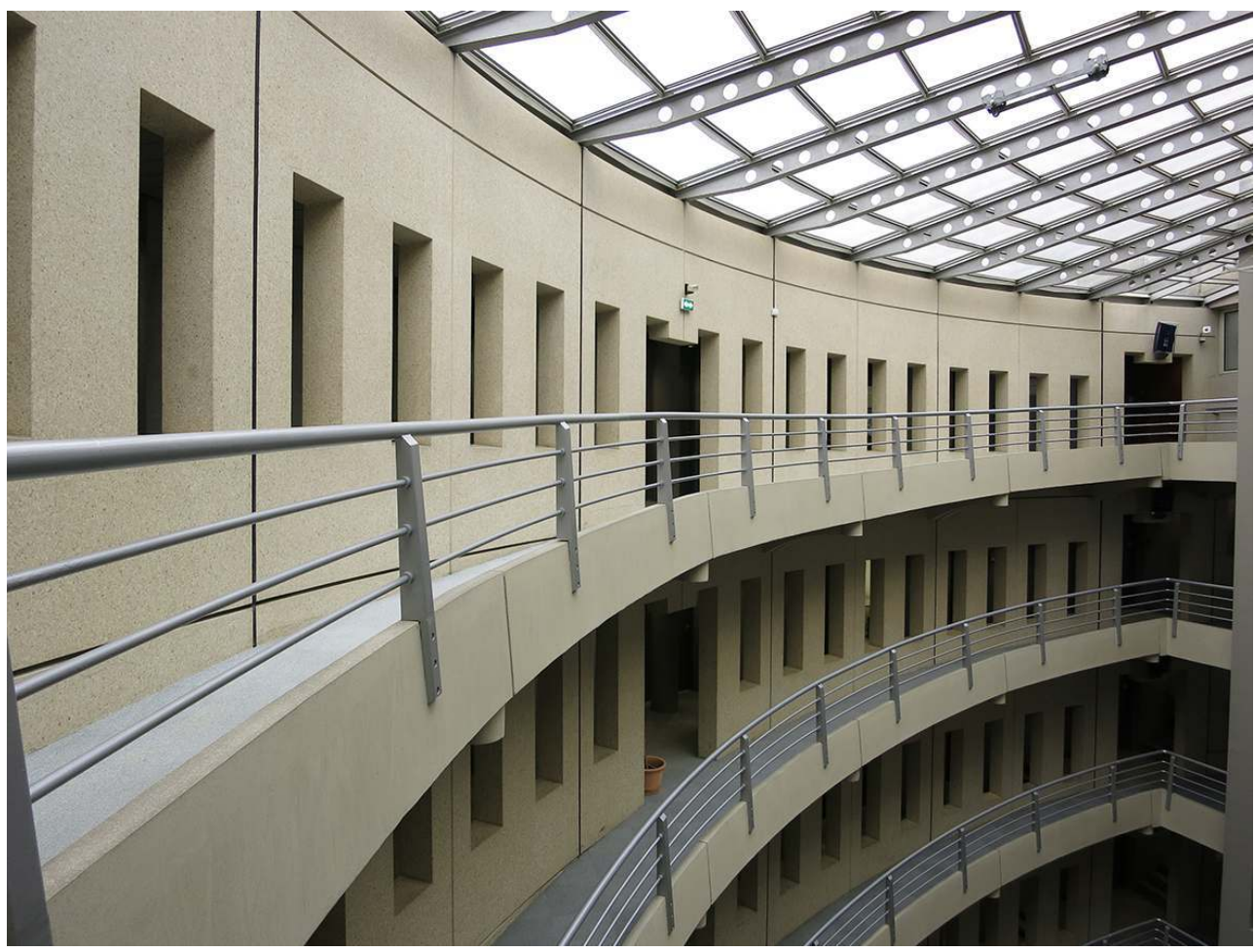

Hôtel de région de PACA. Bloc Plénier (1987-1991, arch. : Claude Parent, Christian Biaggi, Bruno Maurin). Vue actuelle.

Phot. Éléonore Marantz, 2015. @ Éléonore Marantz. 


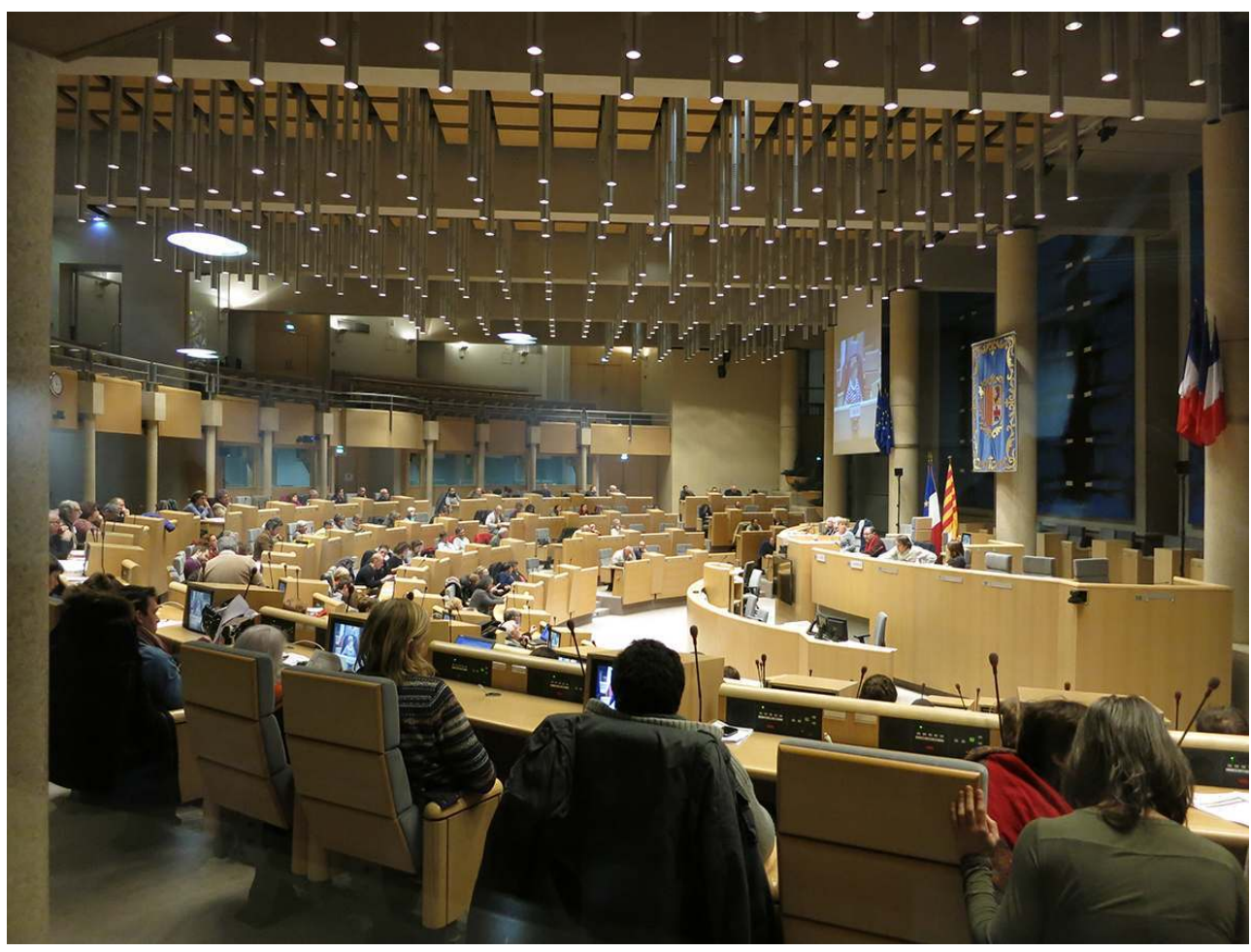

Hôtel de région de PACA. Bloc Plénier (1987-1991, arch. : Claude Parent, Christian Biaggi, Bruno Maurin). Vue actuelle.

Phot. Éléonore Marantz, 2015. ㄷ Éléonore Marantz.

\section{L'hôtel de département, un « totem » architectural}

La relative cohésion politique qui s'affiche lors des cérémonies de pose de première pierre ou d'inauguration ne suffit pas à masquer le fait que Marseille, métropole régionale, est le terrain d'expression de concurrences territoriales. Ainsi, le choix du conseil général de s'implanter dans le quartier de Saint-Just, à la lisière est du « centre » de la ville, répond bien entendu à des opportunités foncières et à la volonté de se situer à la convergence du réseau de transports (autoroutes Nord et Est, ligne 1 du métro) mais aussi à une reconquête plus symbolique. Le conseil général ne cesse de répéter que la construction de l'hôtel du département aura des " effets considérables $»^{51}$ sur le cadre de vie et sur la vie quotidienne des habitants de ce quartier délaissé, qu'elle va participer en ce sens d'un « rééquilibrage social de la cité " $^{52}$. Mais, au-delà des discours, cet emplacement dénué d'urbanité, en réalité peut-être plus subi que choisi, favorise surtout le développement d'une architecture expressive et démonstrative (fig. 33). 


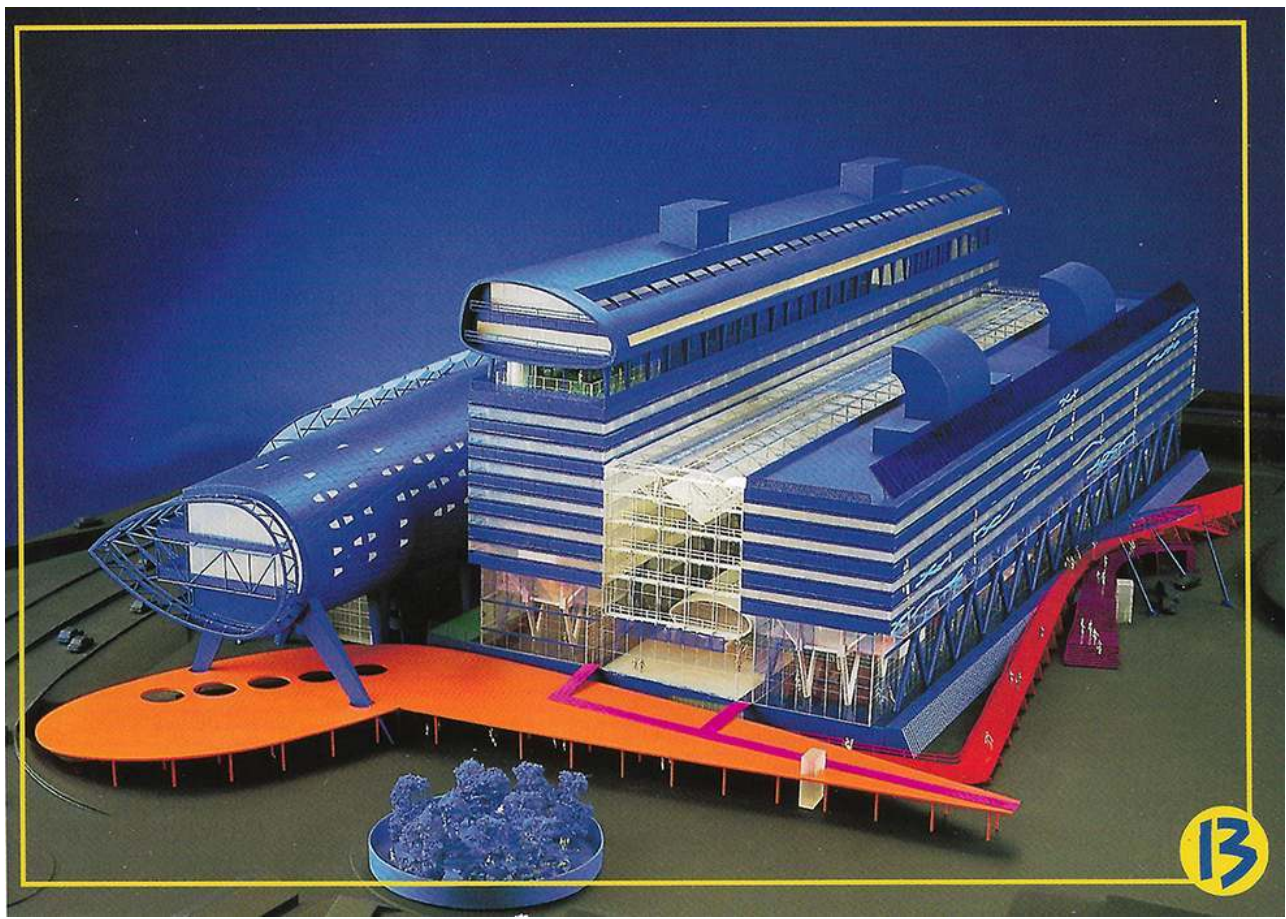

Hôtel de département des Bouches-du-Rhône (1990-1994, arch. : William Alsop, John Lyall). Maquette, carte postale éditée par le conseil général des Bouches-du-Rhône (AD BdR, 2338 W 9).

(c) $\mathrm{AD} B d R$.

Le programme est ambitieux puisque le nouvel hôtel de département doit accueillir 1500 agents territoriaux. William Alsop et son associé John Lyall imaginent un édifice comprenant trois bâtiments parallèles, de hauteurs différentes (fig. 34). 
Figure 34

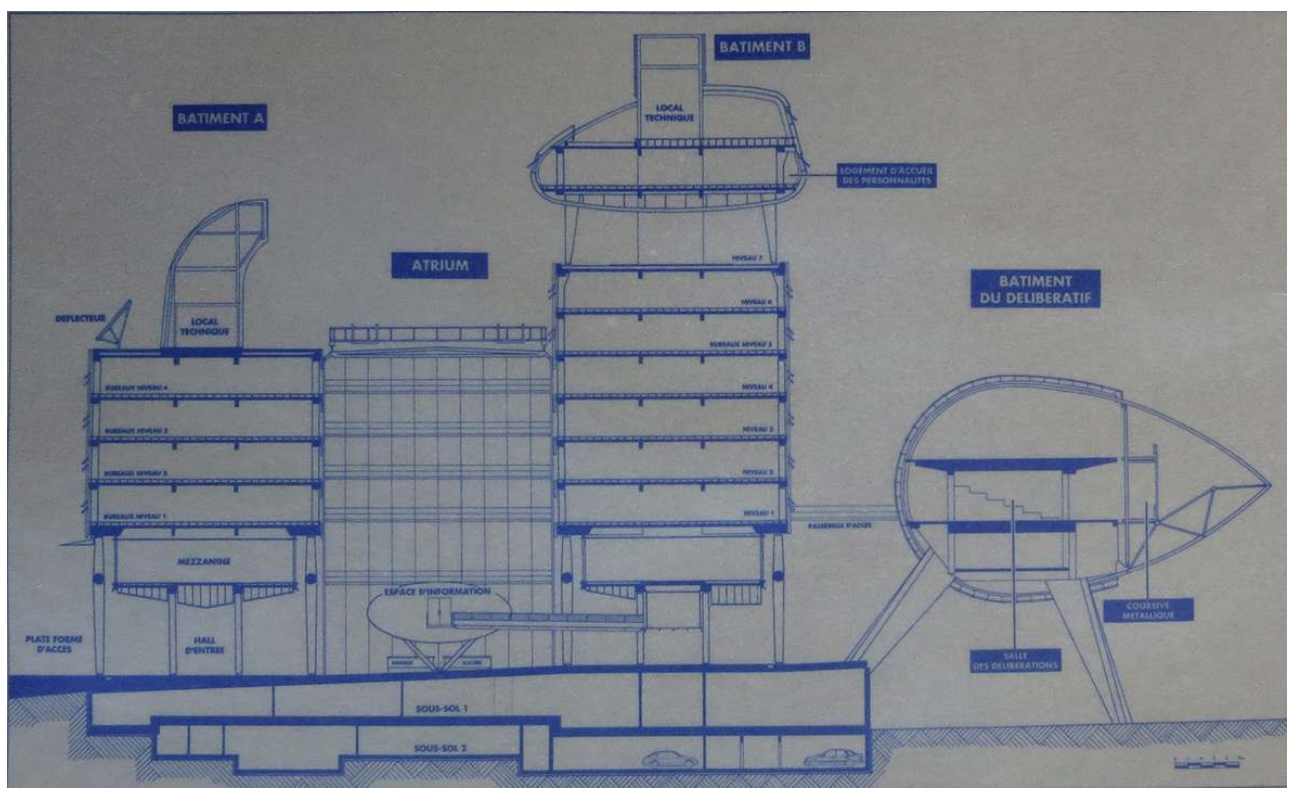

Hôtel de département des Bouches-du-Rhône (1990-1994, arch. : William Alsop, John Lyall). Coupe sur les quatre bâtiments (s.d. circa 1991) (AD BdR, 2338 W 9).

(c) $\mathrm{AD} B d R$.

Deux, destinés aux services administratifs, sont reliés par un atrium vitré pouvant accueillir jusqu'à 4000 personnes lors des grandes manifestations publiques. L'hôtel de département est précédé par un parvis sous lequel sont aménagés deux niveaux de soussol (stationnement et locaux techniques). Cette vaste esplanade, dont le paysage minéral sera bientôt « habité » par une nouvelle salle de concert construite par Denis Sloan ${ }^{53}$, se prolonge à l'intérieur par l'espace clair et tempéré de l'atrium. William Alsop y suspend un étrange volume ovoïde, sorte de «forme libre » en lévitation dédiée aux expositions. Dans les ailes administratives, les bureaux - bénéficiant tous d'un éclairage naturel - se répartissent de part et d'autre d'un noyau central occupé par les locaux techniques et les circulations verticales. L'espace délibératif, où siège l'Assemblée départementale, se détache sur la face sud et prend la forme d'une coque de bateau renversée. L'architecture obéit indéniablement à une logique de décomposition-recomposition dont les références sont à trouver tant dans le New brutalism britannique des années 1950 que dans le courant High-tech qui parcourt alors la scène architecturale internationale. Au-delà d'une stricte (mais réelle) quête de fonctionnalité, William Alsop convoque un imaginaire machiniste et futuriste qui s'exprime dans les formes, la fragmentation spatiale et fonctionnelle, l'exacerbation des réseaux et des connexions, l'omniprésence du métal et du verre. Il le conjugue avec une libre interprétation d'un caractère méditerranéen traduit par la couleur - un bleu profond qui vient "unifier » le bâtiment - et quelques références formelles (coques, voiles, cheminées). L'hôtel du département (fig. 35, 36, 37) est rapidement appelé « le Grand Bleu » ou «Vaisseau bleu », vaisseau par lequel le conseil général imprime indéniablement son empreinte au territoire. Une telle expressivité architecturale incite à émettre l'hypothèse que, dans le cas de l'hôtel du département des Bouches-du-Rhône, le "défaut» de ville invite au triomphe d'une architecture suffisamment éloquente pour devenir un marqueur identitaire, ce dont attestent les discours qui accompagnent sa genèse. 


\section{Figure 35}

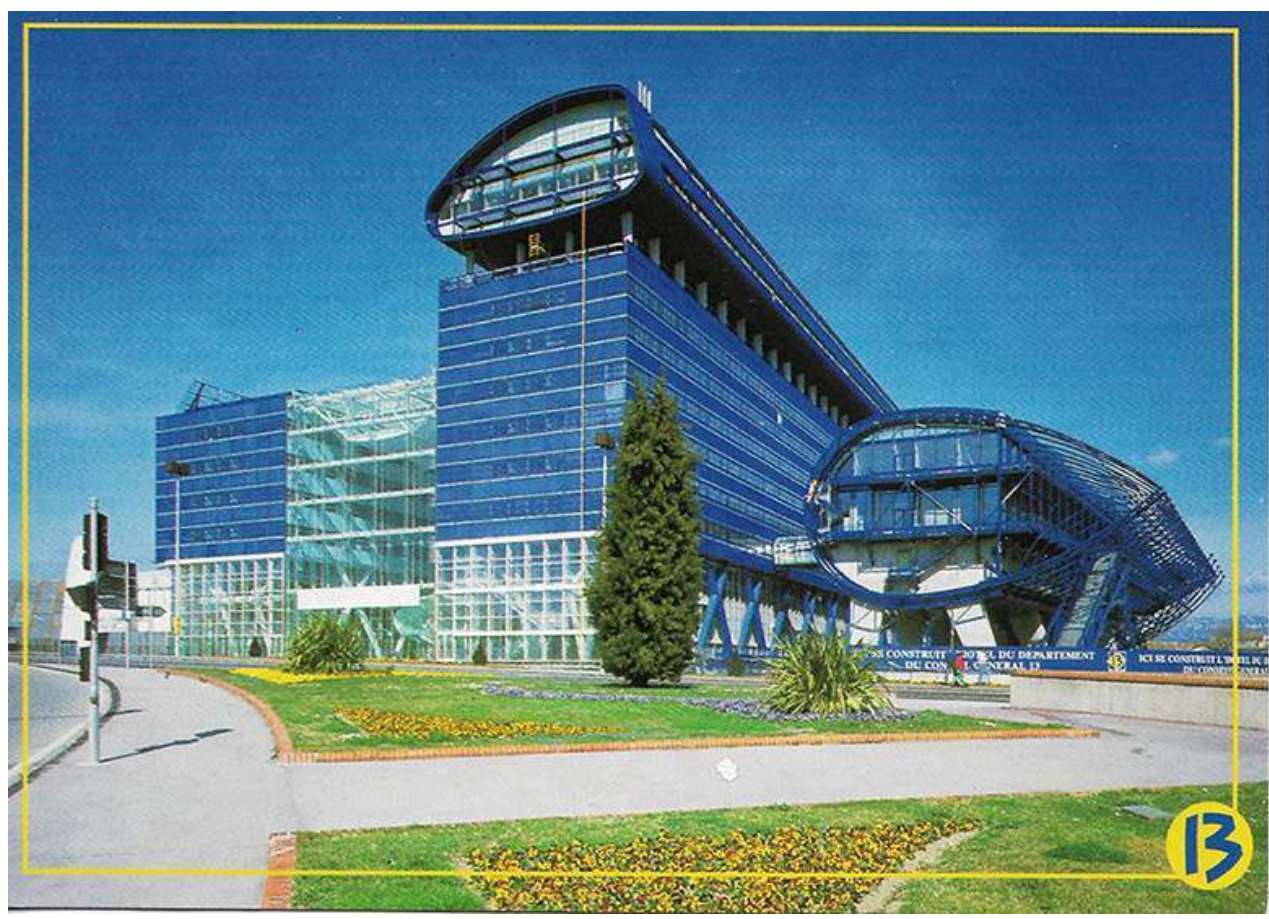

Hôtel de département des Bouches-du-Rhône (1990-1994, arch. : William Alsop, John Lyall). Vue du bâtiment, carte postale éditée par le conseil général des Bouches-du-Rhône ( $A D$ BdR, 2338 W 9). (c) AD BdR. 
Figure 36

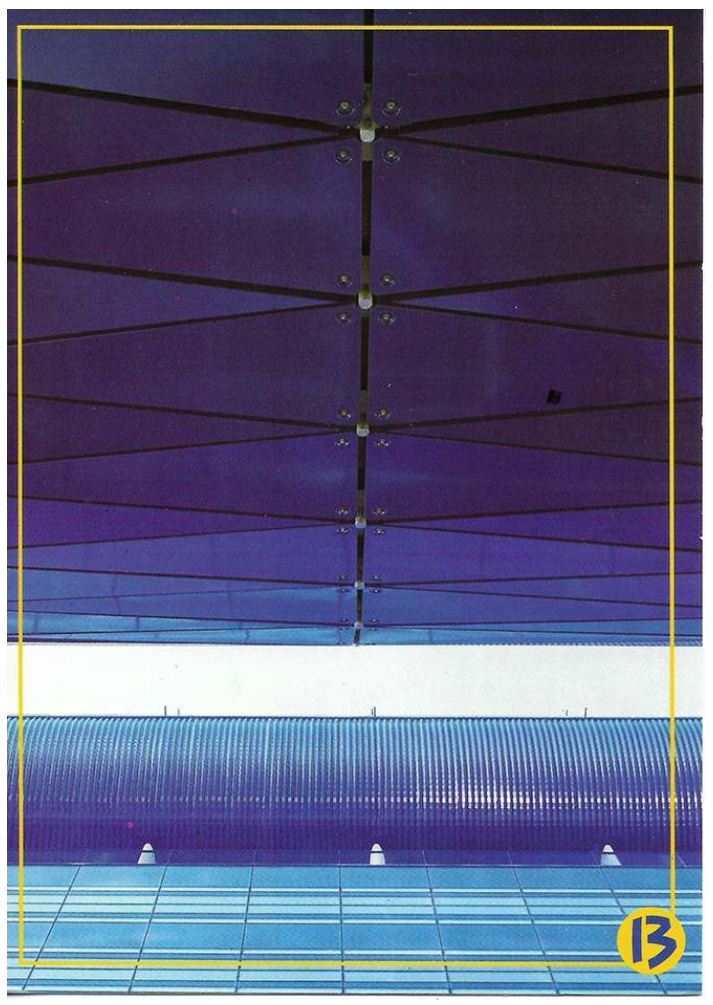

Hôtel de département des Bouches-du-Rhône (1990-1994, arch. : William Alsop, John Lyall). Vue du bâtiment, carte postale éditée par le conseil général des Bouches-du-Rhône (AD BdR, 2338 W 9).

(c) $\mathrm{AD} B \mathrm{BdR}$. 


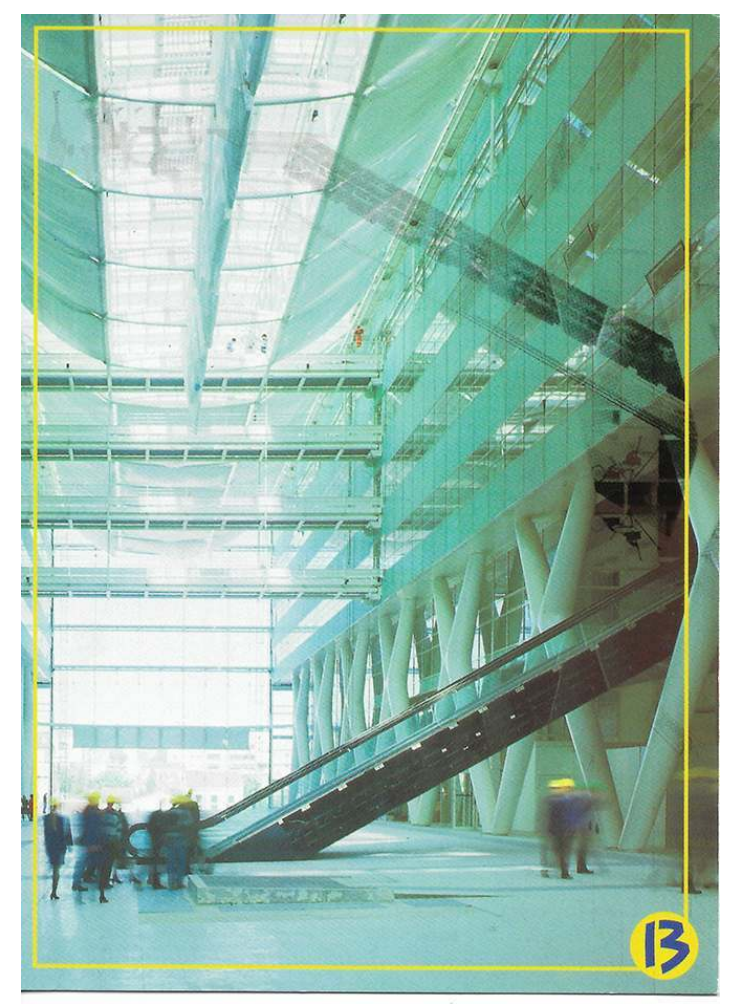

Hôtel de département des Bouches-du-Rhône (1990-1994, arch. : William Alsop, John Lyall). Vue du bâtiment, carte postale éditée par le conseil général des Bouches-du-Rhône (AD BdR, 2338 W 9).

(c) $\mathrm{AD} \mathrm{BdR}$.

\section{Rhétorique et architecture}

La construction de l'hôtel du département donne en effet lieu à une certaine emphase sémantique : un slogan - «Construire pour mieux entreprendre » - est reproduit sur tous les supports de communication du concours d'architecture; de nombreux éléments de langage - «Une architecture résolument tournée vers l'avenir ${ }^{54}$ ", «L'Hôtel du département accessible à tous ${ }^{55}$ ", "Un monument futuriste ${ }^{56}$ " - scandent les discours officiels. Pourtant, l'architecte se défend d'avoir voulu créer l'événement. Il revendique simplement un «bâtiment clair, rationnel, à l'intérieur duquel chacune des parties du programme [est] clairement identifiable», un bâtiment qui «impressionnera les habitants non par sa monumentalité mais parce qu'il invitera à y entrer (...) conçu pour refléter une attitude ouverte ${ }^{57} »$. Et tant pis si la presse architecturale, très attentive au projet tout au long de son élaboration ${ }^{58}$, déplore que William Alsop, dans son architecture comme dans ses déclarations, passe d'un «stade subjectif, émotif, à celui de l'informatif 59 ». Pour le conseil général, l'hôtel du département est « un repère inscrit dans l'histoire, symbole de la décentralisation voulue par Gaston Deferre »; il incarne une institution qui entend « construire une collectivité plus moderne, plus solidaire, plus forte ${ }^{60}$ ». Conscient des enjeux électoraux, politiques et symboliques de cette construction, le conseil général souhaite faire en sorte que les futurs usagers - agents comme administrés - s'approprient le bâtiment au fur et à mesure de son élaboration. Avant le second tour du concours, les cinq projets finalistes avaient ainsi été exposés afin que les fonctionnaires territoriaux 
puissent exprimer leur préférence, initiative inhabituelle même si leur avis eut finalement peu d'incidence ${ }^{61}$. De la même manière, en avril 1990, l'un des principaux quotidiens locaux, Le Méridional, lance une consultation des Marseillais via le Minitel afin de recueillir leurs impressions sur les projets ${ }^{62}$. À l'issue du concours, ces derniers sont exposés à la Foire internationale de Marseille (21 septembre- $1^{\mathrm{er}}$ octobre 1990), une manière pour le conseil général de promouvoir, une fois de plus, son action envers ses administrés mais surtout de montrer comment il a su susciter la créativité au niveau international ${ }^{63}$. Avant que le bâtiment ne commence à sortir de terre, un petit guide est édité à l'attention du personnel ; il y est mis en avant que «le parti architectural (...) particulièrement innovant (...) symbolise à la fois le dynamisme de l'institution et l'esprit de convivialité qui anime son mode de fonctionnement ${ }^{64} »$. Le pouvoir en place est conscient que « l'immeuble de William Alsop devient le conseil général, (...) en exprime la personnalité », qu'il peut désormais apparaître comme un «totem ${ }^{65}$ » et entend bien en tirer parti sur le plan électoral ${ }^{66}$. La collectivité territoriale multiplie les actions publication de plaquettes et de livres sur le bâtiment ${ }^{67}$, éditions de cartes postales et d'objets promotionnels (fig. 38) - visant à faire de l'architecture un outil de communication. D'abord "mis en mots », le nouvel hôtel du département est bientôt ostentatoirement utilisé par des responsables politiques conscients du fait que l'architecture a le pouvoir d'incarner l'institution.

Figure 38

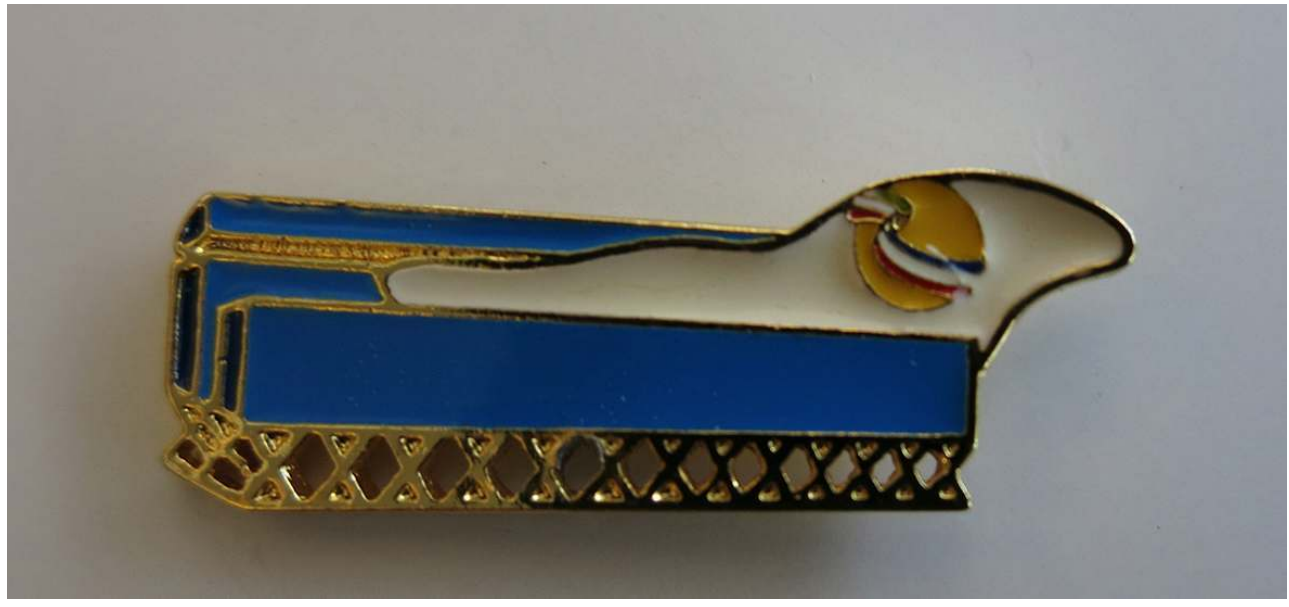

Hôtel de département des Bouches-du-Rhône (1990-1994, arch. : William Alsop, John Lyall). Pin's édité par le conseil général des Bouches-du-Rhône (AD BdR, 2233 W 15).

(c) AD BdR.

Cette logique prévaut aussi en ce qui concerne l'hôtel de région. En janvier 1988, lors de l'inauguration de l'immeuble des Présentines, Jean-Claude Gaudin met en avant que désormais l'institution a un « toit », un « domicile fixe » constituant un élément essentiel de son identité, formulant le vœu que l'édifice devienne à la fois la tribune et la vitrine de l'identité régionale ${ }^{68}$, slogan qui est immédiatement repris dans la presse ${ }^{69}$. En juillet 1989 , lors de la cérémonie de pose de la première pierre du bloc plénier ${ }^{70}$, il insiste sur le fait que «le rôle de l'architecture n'est pas seulement d'offrir les espaces nécessaires à l'activité des hommes, mais d'exprimer aux yeux de tous des réalités importantes bien qu'invisibles par elles-mêmes ». En l'occurrence ici, le bâtiment, par sa situation même à l'entrée de la ville, doit exprimer la vocation de capitale régionale de Marseille (fig. 39). L'hôtel de région doit aussi traduire par « sa beauté et sa modernité, la 
volonté du conseil régional de PACA de préparer efficacement l'avenir » et incarner "l'institution régionale elle-même ». « Le prestige des façades et de l'ensemble [doit être] l'expression du nouveau pouvoir régional», ce qui induit, de fait, une "architecture significative $^{71} »$. Les arguments s'affûtent lorsqu'il s'agit de justifier la différence de coût entre la première et la seconde tranche ${ }^{72}$ : il est alors mis en avant que l'immeuble des Présentines a été conçu et réalisé comme un immeuble de bureaux, avec une trame classique et des matériaux sobres, tandis que le bloc-plénier est «la manifestation physique d'une institution", ce qui se traduit par "l'importance des dimensions, par la rigueur et la clarté de l'architecture, par la beauté des matériaux employés ». C'était bien un monument que l'on attendait de l'architecte ${ }^{73}$. Claude Parent l'avait bien compris et produit, lui aussi, un discours sur l'architecture où il justifie certains choix formels par la nécessité d'exprimer le prestige et l'autorité de l'institution ${ }^{74}$.

Figure 39

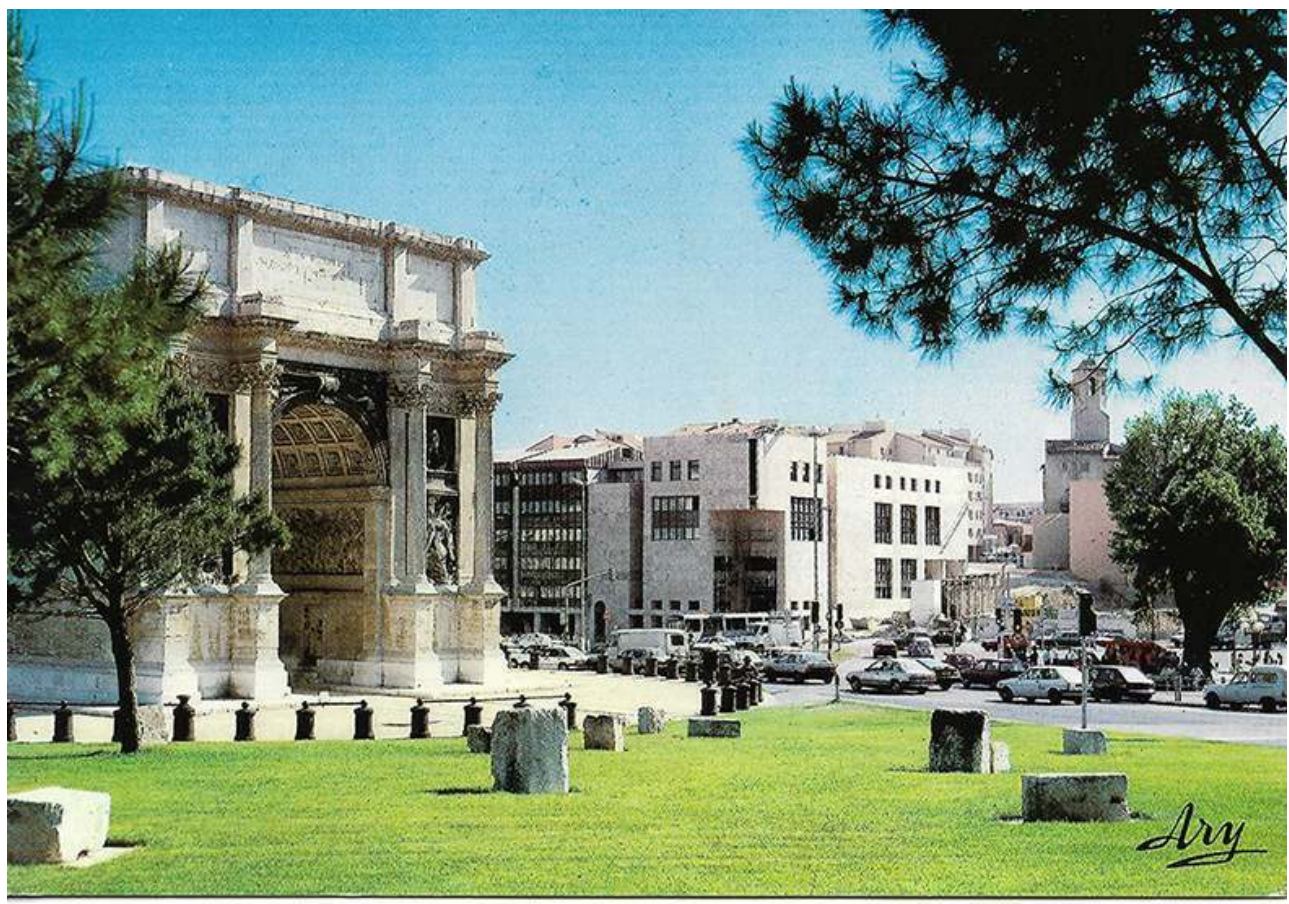

Hôtel de région de PACA (1984-1986, arch. : Jean-Michel Battesti ; 1987-1991, arch. : Claude Parent Christian Biaggi, Bruno Maurin). Carte postale (s.d. circa 1990's), collection de l'auteur.

\section{Épilogue : Créativité et fabrique d'une « image de marque »}

Cette rhétorique montre que l'architecture publique est désormais un terrain où s'expriment identités et concurrences institutionnelles. Pour le conseil général des Bouches-du-Rhône, l'architecture offre l'opportunité de se réinventer tandis que pour le conseil régional de PACA, de création beaucoup plus récente, elle doit permettre de s'imposer comme un échelon administratif structurant. Par conséquent, la mesure, la pondération et la recherche d'un certain consensus guident la région tandis que le département, qui souhaite accroître son rayonnement, a l'audace de choisir le projet très marqué architecturalement parlant - d'un architecte britannique encore presque 
inconnu. Plus généralement, l'engagement des collectivités en faveur de l'architecture permet d'évaluer l'incidence de la politique des concours. Face à l'ambition affichée de renouveler le «corps» travaillant à la fabrique de l'architecture publique, le «cas » marseillais tend en effet à montrer que ce défi est relevé avec succès: Jean-Michel Battesti comme William Alsop sont de jeunes professionnels qui n'ont pas encore de réalisations significatives à leur actif et qui, grâce à l'immeuble des Présentines et à l'hôtel de département, vont donner une impulsion décisive à leur carrière. Dans une certaine mesure, la réalisation du bloc-plénier de l'hôtel de région joue ce même rôle impulsif pour Claude Parent en lui permettant de renouer avec la commande. Toutefois, si les concours lancés au tournant des années 1980 et 1990 ont encore un effet d'émulation réel, leur succès est tel (de l'ordre de 1200 par an ${ }^{75}$ ) qu'ils se muent rapidement en des consultations restreintes, puis en de simples mises en concurrence, ce qui aura un fort impact sur l'ouverture initialement souhaitée.

Pour l'heure, à Marseille, hôtel de région et hôtel de département expriment surtout en des termes différents - presque antagonistes du point de vue formel - à quel point l'architecture publique met en tension les concepts de pouvoir et de représentativité, pose la question de la ville et du monument, de la fabrique du discours et de processus de validation de l'architecture. Toutes ces interrogations ouvrent sur une autre, plus fondamentale: au motif d'un retour de la dimension symbolique et signifiante de l'architecture, cette dernière serait-elle devenue une «image de marque »? Serait-on passé au cours $d u x^{e}$ siècle, en matière d'architecture publique, de la culture du monument à celle de l'équipement puis, au moment de la décentralisation, à une " branding architecture » obéissant à d'autres impératifs et temporalités? Cette hypothèse semble d'autant plus importante à considérer que les recompositions institutionnelles et territoriales actuelles posent, parfois avec beaucoup d'acuité, la question de l'obsolescence d'architectures conçues pour incarner la pérennité.

\section{NOTES}

1. - BODINEAU, Pierre. Histoire de la décentralisation. Paris : PUF, 1993 ; OHNET, Jean-Marc. Histoire de la décentralisation française. Paris : Librairie générale française, 1996.

2. - AGULHON, Maurice, BECKER, Annette, COHEN, Évelyne (éd.). La République en représentations. Autour de l'œuvre de Maurice Agulhon. Paris: Publications de la Sorbonne, 2006.

3. - AMOUROUX, Dominique, SARRAMON, Christian. Bâtiments publics. Une nouvelle génération. Paris : Le Moniteur, 1980 ; CHASLIN, François (dir.). Architecture 1980. Doctrines et incertitudes. Les Cahiers de la recherche architecturale, $\mathrm{n}^{\circ}$ 6-7, 1980 ; LENGEREAU, Éric. « L'Architecture entre culture et équipement (1965-1995)». Vingtième siècle. Revue d'histoire, vol. 53, nº 1, p. 112-123; LUCAN, Jacques. Architecture en France (1940-2000) : histoire et théories. Paris : Le Moniteur, 2001 ; MIQCP. Architectures publiques 1990. Cat. exp., Paris, centre Georges Pompidou, 28 mars-7 mai 1990. Liège : Mardaga, 1990 ; MONNIER, Gérard. L'Architecture moderne en France. T. 3, De la croissance à la compétition, 1967-1999. Paris : Picard, 2000.

4. - LAMBERT, Guy, MARANTZ, Éléonore. «Enseignement de l'architecture, architectures de l'enseignement. Les écoles d'architecture en France depuis 1960 ». Dans Ibid. (dir.). Écoles 
d'architecture - Architectures d'écoles. Paris : Éditions Dominique Carré, à paraître en 2018. Les unités pédagogiques d'architecture (UPA ou UP) créées au début de l'année 1969 préfigurent les futures écoles d'architecture (nom que ces établissements prennent en 1985-1986) et les actuelles écoles nationales supérieures d'architecture (ENSA, depuis 2001).

5. - VIOLEAU, Jean-Louis. Les Architectes et Mai 68. Paris : Éditions Recherches, 2005.

6. - MARANTZ, Éléonore. «L'université et ses architectes. Mode de désignation et processus de commande en question ». Dans BOURILLON, Florence, MARANTZ, Éléonore, MÉCHINE, Stéphanie, VADELORGE, Loïc (dir.). De l'Université de Paris aux universités d'T̂le-de-France. Rennes : PUR, 2016, p. 223-239.

7. - LENGEREAU, Éric. L'État et l'architecture (1958-1981). Une politique publique ? Paris : Picard/Comité d'histoire du ministère de la Culture, 2001.

8. - Décret 93-1270 du 29 novembre 1993 portant application de l'article 18-1 de la loi MOP. ANDRIEUX, Jean-Yves, SEITZ, Frédéric. Pratiques architecturales et enjeux politiques. France, 1945-1995. Paris : Picard, 1998, p. 15-16.

9. - TILMONT, Michèle. «Architectures publiques au pluriel ». Dans MIQCP. Architectures publiques 1990. Op. cit., p. 9-10.

10. - GUIHEUX, Alain. « Comment choisir ». Dans MIQCP. Architectures publiques. Op. cit., p. 11.

11. - En tant que divisions administratives, les départements ont été créés en 1789 et les régions en 1956.

12. - Dans la région PACA, un établissement public régional est créé à la faveur de la loi du 5 juillet 1972 ; il est remplacé par le conseil régional de PACA en 1974. À partir du 2 mars 1982, le président du conseil régional exerce l'exécutif régional et, entre janvier 1983 et janvier 1985, l'État transfère des compétences aux régions, notamment en matière d'éducation et de formation professionnelle. À la faveur de la loi du 10 juillet 1985 qui établit l'élection pour 6 ans, au suffrage universel, des conseillers régionaux, 117 conseillers sont élus le 16 mars 1986 (Conseil régional PACA. Les grandes dates. Archives de la région PACA (désormais ARPACA) V 181/102).

13. - BROCHART, Antoine. «Les Hôtels de région. Architectures républicaines à l'aune de la décentralisation ». Dans COHEN, Évelyne, MONNIER, Gérard (dir.). La République et ses symboles : un territoire de signes. Paris : Publications de la Sorbonne, 2013, p. 347-359; DEFILLON, Julien. L'Hôtel de région: Bourgogne. Lyon: Lieux Dits, coll. «Parcours du patrimoine», 2015. Voir également dans ce numéro: DEFILLON, Julien. «La région Bourgogne: un hôtel de région construit en secteur sauvegardé dans le goût des années 1970 ", In Situ [En ligne], 34 | 2018, mis en ligne le 04 mai 2018, consulté le 04 mai 2018. URL : http://journals.openedition.org/insitu/15993.

14. - SOFRACIM (Société française de construction et de développement immobiliers, 1984), puis SOMICA (Société marseillaise communale d'aménagement et d'équipement, aménageur de la ZAC Sainte-Barbe, 1984-1986) et enfin SEMADER (1987) (note de Franck Tassy (Comité régional de promotion et de relations extérieures, PROMO PACA) à Maurice Battin (chef de cabinet du président du conseil régional), 25 janvier 1988, ARPACA $35 \mathrm{~W} 17$; allocution de Jean-Claude Gaudin pour la pose de la première pierre de la deuxième tranche de l'hôtel de la région, 10 juillet 1989, ARPACA 35 W 97).

15. - Le concours de la première tranche (1984) est organisé «en vue de l'étude, et éventuellement de la réalisation, de l'ensemble de bureaux destiné au Conseil régional » mais le règlement précise que, dans la perspective d'une seconde tranche, «il est demandé aux concurrents de réfléchir, d'imaginer et de proposer par le biais d'esquisses (...) un aménagement cohérent entre cette première tranche et les différents éléments du programme qui pourraient être réalisés sur les terrains environnants » (SOFRACIM. "Préambule ». Règlement du concours. 20 juillet 1984, ARPACA 35 W 83).

16. - Sur les 56 agences approchées, 32 sont installées dans les Bouches-du-Rhône, 16 à Paris ou dans la région parisienne (SOFRACIM. Appel à candidature auprès des architectes. s.d. circa juillet 1984, ARPACA 35 W 84). 
17. - Au cours des années 1970 et 1980, Ricardo Bofill est très actif en France à Cergy-Pontoise (place Majeure, 1975 ; Les Colonnes de Saint-Christophe, 1986), Marne-la-Vallée (Abraxas, 1982 ; Les Arcades du lac Viaduc, 1982), Saint-Quentin-en-Yvelines (Les Temples du lac, 1986), Paris (Les Échelles du Baroque, 1986), Montpellier (place du Nombre d'or, 1985 ; Port-Juvenal Antigone, 1989 ; Les Échelles de la ville, 1989 ; hôtel de région, 1986-1989) pour la réalisation de quartiers d'habitation et d'édifices publics. Sur l'hôtel de région de Languedoc-Roussillon (1986-1989), voir GANIBENC, Dominique. "L'Hôtel de région en Languedoc-Roussillon (1986-1989), un chantier de recherche ». Patrimoines du sud [en ligne], 3/2016, mis en ligne le 9 février 2016, consulté le 9 mai 2017, URL : http://inventaire-patrimoine-culturel.cr-languedocroussillon.fr.

18. - Avant d'être soumis au jury, les six projets font part d'une triple expertise de la part de l'Agence d'urbanisme de l'agglomération marseillaise (AgAM), de la SOFRACIM et de l'architecte Thierry Durousseau qui les qualifie de " glaçon dans le coin », « Botta, Moneo et Gardelle, avec un peu de style international », "style reconstruction », " architecture et ficelle », " modernisme tardif » et « l'aqueduc et le rempart », déplorant au passage que seulement deux projets posent la problématique urbaine (hôtel de Région. Note sur les réponses des concurrents, 2 octobre 1984, ARPACA $35 \mathrm{~W} 84$ ).

19. - Compte rendu de la réunion du jury du 12 novembre 1984, s.d. circa 1984 (ARPACA 35 W 84). 20. - Lettre de Michel Pezet, président du conseil régional, à Alain Caen, directeur général de la SOFRACIM, 11 décembre 1984 (ARPACA 35 W 84).

21. - Conseil régional. Direction de l'administration générale et du personnel, hôtel de Région $1^{\text {re }}$ tranche. Note sur l'avancement du projet, 28 octobre 1985 (ARPACA 35 W 85).

22. - Précisément entre le 5 et le 8 décembre 1987 (note de Franck Tassy (Comité régional de promotion et de relations extérieures, PROMO PACA) à Maurice Battin (chef de cabinet du président du conseil régional), 25 janvier 1988, ARPACA $35 \mathrm{~W} 17)$.

23. - Le permis de construire de la seconde tranche est signé le 5 janvier 1988 par le maire de Marseille et par le préfet de région (discours de Jean-Claude Gaudin lors de l'inauguration de l'immeuble des Présentines, 7 janvier 1988, ARPACA V 181/102; visite de chantier de l'hôtel de région ( $2^{\mathrm{e}}$ tranche), lundi 26 mars 1990, ARPACA $\left.215 \mathrm{~W} 20 \mathrm{~B} 16\right)$.

24. - Parmi les candidatures reçues (56), une majorité (34) émanait d'agences locales mais des architectes tels que Claude Parent, Bernard Desmoulin, Alain Sarfati (AREA) ou encore Paul Chemetov et Borja Huidobro (AUA) associés ou non à des acteurs locaux, s'étaient aussi portés candidats (Région PACA, hôtel de région, $2^{\mathrm{e}}$ tranche. Dossier de consultation des concepteurs. Examen des candidatures d'architectes, 10 février 1987, ARPACA 35 W 96). Les concurrents sélectionnés pour le second tour - Battesti, Boillat, Chaussat, Meillassoux, Parent et l'agence Sud (Rapport du président du conseil régional, 23 mars 1987, ARPACA 35 W 96) - devaient fournir un plan de masse au $1 / 500^{\mathrm{e}}$, un plan schématique des niveaux au $1 / 200^{\mathrm{e}}$, des vues perspectives du projet dans son environnement, une présentation esquissée des façades au $1 / 200^{\mathrm{e}}$, une maquette de volume au $1 / 200^{\mathrm{e}}$ et une note explicative de cinq pages dactylographiées (Région PACA, hôtel de région $2^{\mathrm{e}}$ tranche. Dossier de consultation des concepteurs. Règlement, décembre 1986, ARPACA $35 \mathrm{~W}$ 96). Les critères de jugement du concours étaient la qualité architecturale et l'intégration de l'édifice dans le site de la place d'Aix, la sécurité d'ensemble du bâtiment, notamment de la salle plénière, et les performances en matière de coût d'entretien et de fonctionnement (conseil régional. Direction générale des services, Rapport du président du conseil régional, 22 décembre 1986, ARPACA 35 W 95 ; Région PACA, hôtel de Région $2^{\mathrm{e}}$ tranche. Dossier de consultation des concepteurs. Programme, décembre 1986, ARPACA 35 W 95).

25. - Claude Parent est certes reconnu mais il ne tire pas sa renommée de la construction de bâtiments publics (JEANROY, Audrey. Claude Parent, architecture et expérimentation, 1942-1996: itinéraire, discours et champ d'action d'un architecte créateur en quête de mouvement. Thèse d'histoire de l'art contemporain sous la direction de Jean-Baptiste Minnaert. Tours : université de Tours, 2016). 
26. - Les travaux de Perig Bouju abordent cette question sur une période plus longue (BOUJU, Perig. Architecture et lieux de pouvoir en Bretagne (XVIII $-\mathrm{XX}^{e}$ siècles). Thèse d'histoire de l'art sous la direction de Jean-Yves Andrieux. Rennes : université de Rennes, 2011).

27. - La candidature de Popa Costel (Roumaine) est déclarée hors concours car arrivée hors délai (Conseil général des Bouches-du-Rhône. Concours international de concepteurs. Liste des candidats, s.d. circa mars 1990, AD Bouches-du-Rhône 2338 W 12 ; Conseil général des Bouchesdu-Rhône. Cahier d'enregistrement des projets en réponse au concours d'architecture du futur hôtel du département. $1^{\text {er }}$ tour, s.d. circa mars 1990 (AD BdR 2338 W 12).

28. - POGGI, Jacques. Compte rendu de la réunion du 5 septembre 1989 en vue de la préparation du comité de pilotage du 8 septembre 1989 (AD BdR, 2333 W 26).

29. - Si au XIX ${ }^{\mathrm{e}}$ siècle, le département organise peu de concours (JASMIN, Denise. "L'architecture publique civile ». Dans VIAL, Marie-Paule (dir.). Marseille au XIX eiècle. Rêves et triomphes. Cat. exp., Marseille, musées de Marseille, 16 novembre 1991-15 février 1992. Marseille/Paris : Musées de Marseille/RMN, 1991, p. 126-155), ils se multiplient après la Seconde Guerre mondiale à la faveur de la réorganisation des services de la construction qui intervient à l'échelle du territoire national.

30. - Hôtel de département de l'Hérault (Montpellier, Hérault, 1976: décision de construction, 1980 : concours, 1985-1987 : construction, arch. : AUA de Crouzet, Michel, Tourre) (plaquettes de présentation de l'hôtel de département de l'Hérault, AD BdR, $132333 \mathrm{~W} 26$ ).

31. - Cela transparaît à tous les stades de la consultation, tant dans les dossiers élaborés à l'attention des concepteurs que dans les documents mis à la disposition des membres du jury (liste des candidats, portfolio présentant les projets des candidats, carnet de jury, etc.) ou encore au travers des campagnes de communication menées à l'attention du grand public (AD BdR, $2338 \mathrm{~W} 10)$.

32. - La commission technique est composée de De Rosbo et Montaudon (parti fonctionnel et programme), de Sbriglio, Battesti et Perrinel (parti architectural), de Dumont et Savasta (parti technique), de Paulze (analyse économique) et des directeurs du département et de la cellule opérationnelle du projet (parti utilisateurs) (conseil général des Bouches-du-Rhône. Concours international de concepteur. Hôtel du département. Commission technique, Compte rendu de la réunion plénière du 22 mai 1990, s.d. circa mai 1990, AD BdR, 2338 W 11).

33. - Conseil général des Bouches-du-Rhône, Concours international de concepteurs. Liste des candidats, s.d. circa mars 1990 (AD BdR, $2338 \mathrm{~W}$ 12).

34. - Les architectes intéressés par la consultation ont jusqu'au 19 mars 1990 pour se porter candidats (conseil général des Bouches-du-Rhône, Concours international de concepteurs. Liste des candidats, s.d. circa mars 1990, AD BdR, 2338 W 12 ; Conseil général des Bouches-du-Rhône, Cahier d'enregistrement des projets en réponse au concours d'architecture du futur hôtel du département. $1^{\mathrm{er}}$ tour, s.d. circa mars 1990, AD BdR $2338 \mathrm{~W} 12$ ).

35. - Liste des membres du jury présents le 2 avril 1990 : Lucien Weygand (président du conseil général, président du jury) ; François Bernardini, Francis Caccintolo, Michel Coullomb, Alain Decamps, Roger Donadio, Georges Grolleu, Jean-Noël Guérini, Francis Pélissier, André Samat, Robert Villani, Claude Vulpian (conseillers régionaux) ; Jean-Louis Champsaur, André Dunoyer de Segonzac, Massimiliano Fuksas, Pierre Garnier, Lucien Kroll, John Miller, Manolo NunezYanowsky, Fernand Ramos, Rudy Ricciotti, Peter Wilson (maîtres d'œuvre) ; Claude Bussière, André Ducourneau, Christian Ferial, Patrice Goulet, André Heurte, Albert Hini, Jean-Paul Louvet, Gérard Porcell, René Poux (personnalités politiques et administratives désignées par le président); Louis Philibert, Eugène Minot (membres du jury avec voix consultative); Daniel Conte, Robert Vigouroux, Francis Soler, Yves Dauge et Paolo Portoghesi sont absents et excusés (Procès-verbal de la réunion de jury chargé de désigner le lauréat du concours international d'architecture pour la réalisation de l'hôtel du département, 8 juin 1990, AD BdR, 2338 W 11). 
36. - Conseil général des Bouches-du-Rhône. Concours international de concepteur. Compte rendu des réunions du jury, 3 avril 1990 (AD BdR, 2338 W 11); entretien avec John Miller, 30 novembre 2017.

37. - Ils ont construit en Italie, aux États-Unis et en France (notamment le siège d'IBM à La Défense, 1983-1985). Ils ont également participé au concours pour le palais d'Iéna (1989).

38. - Concours d'architecture. Hôtel du département. Carnet de jury, 7-8 juin 1990 (AD BdR, 2233 W 18).

39. - Procès-verbal de la réunion de jury chargé de désigner le lauréat du concours international d'architecture pour la réalisation de l'hôtel du département, 8 juin 1990 (AD BdR, 2338 W 11).

40. - Le Grand Pavois (Marseille, $8^{\mathrm{e}}$ arrt., 1972-1975, arch. : Jean et Georges Delbes, Bernard Laville, Guillaume Gillet) est un immeuble d'habitation et de bureaux, longtemps le plus élevé de la ville, construit dans les quartiers Sud, sur le rond-point du Prado.

41. - ARPACA 35 W 77, ARPACA 35 W 78, ARPACA 35 W 79.

42. - La place de la Porte-d'Aix (actuelle place Jules-Guesde) était une place circulaire s'organisant autour d'un arc de triomphe (1823-1837, arch. : Michel-Robert Penchaud). La percée de l'autoroute Nord (A7, 1971), tout comme les récents aménagements réalisés dans le cadre du projet Euroméditerranée (2015-2016) ont fait évoluer sa physionomie.

43. - Voir notamment: Opération ZAC Sainte-Barbe, triangle Sainte-Barbe. $2^{e}$ campagne de démolition: RHI (Résorption de l'habitat insalubre) Les Chapeliers - RHI rue d'Aix, Étude de la capacité de reconstruction des terrains libérés par les démolitions, étude réalisée par B. Dianoux et V. d'Ortoli, architectes DPLG, pour la ville de Marseille avec la SOMICA comme maître d'ouvrage délégué, 28 mars 1983 (ARPACA $35 \mathrm{~W} 80$ ).

44. - MARANTZ, Éléonore. "Les prisons de Marseille aux xixe et xxe siècles, un laboratoire architectural au service d'un projet social?». Livraisons d'histoire de l'architecture, 27|2014, p. 63-73.

45. - « Hôtel de Région ». Marseille, Architecture à Marseille depuis un siècle, $\mathrm{n}^{\circ}$ 219, décembre 2007, p. 96-97. Extrait de la présentation de l'immeuble des Présentines par Jean-Michel Battesti.

46. - Ibid.

47. - La façade est traitée « en pierre calcaire de type Magny rosé rappelant la pierre de La Couronne ». Ibid.

48. - Note de Franck Tassy (Comité régional de promotion et de relations extérieures, PROMO PACA) à Maurice Battin (chef de cabinet du président du conseil régional), 25 janvier 1988 (ARPACA $35 \mathrm{~W}$ 17).

49. - Le béton devait initialement être laissé brut mais, suite à quelques déboires dans sa mise en œuvre, architectes et entreprise générale responsable du gros-œuvre (Mistral travaux) opteront pour un béton poli recouvert d'une couche de lasure uniforme beige (MORELLI, Philippe. « Marseille. L’Hôtel de région rénove ses bétons ». Le Moniteur, 24 mai 1991, p. 70-71).

50. - « Hôtel de Région ». Marseille, Architecture à Marseille depuis un siècle, $\mathrm{n}^{\circ} 219$, décembre 2007, p. 96-97. Extrait de la présentation du «bloc plénier » par Claude Parent ; Descriptif de la seconde tranche, s.d. circa 1987-1991, (ARPACA V 181 B 105).

51. - WEYGAND, Lucien. La Lettre du président: L'Hôtel du département des Bouches-du-Rhône dans les quartiers de Saint-Just. Les Chartreux, s.d. circa 1990 (AD BdR, 2338 W 9).

52. - La lettre du Conseil général, numéro spécial: Hôtel du département, s.d. circa automne 1990 (AD BdR, 2233 W 17). Construction du nouvel Hôtel du département. Étude d'impact, juillet 1990, dressée par l'Atelier coopératif pour l'aménagement et l'architecture (ACAA), document dactylographié, 96 pages (AD BdR, $2338 \mathrm{~W}$ 9).

53. - Le Dôme (1993-1994, arch. : Denis Sloan).

54. - L'Hôtel du département des Bouches-du-Rhône. Une architecture résolument tournée vers l'avenir, plaquette publiée par le conseil général des Bouches-du-Rhône, s.d. circa 1993 (AD BdR, 2338 W 9). 
55. - L'Hôtel du département accessible à tous, plaquette publiée par le conseil général des Bouchesdu-Rhône, 25 juin 1993 (AD BdR, 2338 W 10).

56. - Voisinage. Journal d'information de Saint-Just, nº 1, février 1992.

57. - Propos de William Alsop repris dans L'Hôtel du département des Bouches-du-Rhône. Une architecture résolument tournée vers l'avenir, plaquette publiée par le conseil général des Bouchesdu-Rhône, s.d. circa 1993, p. 6 (AD BdR, 2338 W 9).

58. - Les revues de presse réalisées par le conseil général en témoignent ( $A D$ BdR, $2233 \mathrm{~W} 15$ et 2233 W 16).

59. - MCL. « Hôtel du département, Marseille ». Techniques et architecture, $n^{\circ}$ 401, mai 1992, p. 19.

60. - Conseil général des Bouches-du-Rhône. Hôtel du département des Bouches-du-Rhône. Marseille, CG13, 1994, non paginé.

61. - Sur 457 visiteurs, 141 se sont exprimés, 15 par des remarques et 126 par des votes. La préférence des visiteurs va sans conteste au projet de Norman Foster (65 voix +8 voix à égalité avec le projet de Pascal Urbain) dont ils retiennent "l'esthétique ", le caractère "séduisant ", « moderne » et « futuriste », puis à celui de Pascal Urbain (17 voix + 8 voix à égalité avec le projet de Norman Foster) pour son côté " compact », «fonctionnel » et sa " dimension humaine ", celui d'Urquito (17 voix) qui constitue "un signal tout en dégageant de l'espace», de Jourda et Perraudin (16 voix mais le projet est souvent cité en $2^{\text {e }}$ position par les personnes lui ayant préféré celui de Foster) dont les visiteurs retiennent l'aspect « clair et original » et la « place faite aux espaces verts" alors que le projet d'Alsop ne recueille que 3 voix (AD BdR, 2338 W 12). Certains bulletins - «À Marseille, pas de tour de La Défense!», "C'est Alsop que j'aime!»déposés dans l'urne publique sont conservés ( $\mathrm{AD} B \mathrm{dR}, 2338 \mathrm{~W} 11)$.

62. - VAN LEDE, Geneviève. "Cinq projets pour un Hôtel du département ». Le Méridional, 5 avril 1990.

63. - Parallèlement, le conseil général adresse à chacun des candidats le recueil des 84 propositions suscitées par la consultation (AD BdR, $2338 \mathrm{~W} 12$ ).

64. - Conseil général des Bouches-du-Rhône. Nouvel Hôtel du département. Petit guide à l'attention des personnels, 1992, p. II (AD BdR, 2233 W 16). Ce guide est publié à l'occasion de la cérémonie de pose de la première pierre (18 février 1992).

65. - Cela avait été mis en avant par l'agence de communication EUROCOM Public qui rédige une note en mars 1993 dans le cadre de la mission « Veille de communication » (AD BdR, 2233 W 11).

66. - L'inauguration du nouvel hôtel du département, prévue en février 1994, coïncide avec les élections cantonales.

67. - SPENS, Michael (dir.). L'Hôtel du département des Bouches-du-Rhône. Le Grand Bleu. Marseille. William Alsop. Marseille/Londres, CG13/AD Academy, 1994 ; Conseil général des Bouches-duRhône. Hôtel du Département. Marseille, CG13, 1994.

68. - Discours de Jean-Claude Gaudin lors de l'inauguration de l'immeuble des Présentines, 7 janvier 1988 (ARPACA V 181/102).

69. - BERTAUDON, Yves. "Hôtel de la Région. Une inauguration sous le signe du Grand Sud". Publications commerciales de Marseille et des Bouches-du-Rhône, mardi 12 janvier 1988, une et p. 2 ; DELON, Yves. «Conseil régional. La vitrine de l'identité régionale ». Le Dauphiné, 9 janvier 1988, une et page non déterminée; CHANAL, Jean-Pierre. "La Région en ses murs». Le Provençal, 8 janvier 1988, une et p. 21 ; CANTELAR, Henri de. "Un toit pour la région PACA ». L'Antenne, 11 janvier 1988, une et p. 16.

70. - Allocution de Jean-Claude Gaudin pour la pose de la première pierre de la deuxième tranche de l'hôtel de la Région, 10 juillet 1989 (ARPACA 35 W 97). Les citations qui suivent dans ce paragraphe sont extraites de son discours.

71. - Document sans titre (ARPACA 35 W 95).

72. - Pour rappel, le budget alloué à la construction de l'immeuble des Présentines est de 67 millions de francs (valeur 1985) tandis que celui réservé à la construction du «bloc plénier » 
atteint 157662000 francs (valeur 1987). Dans une note destinée à justifier le coût de l'hôtel de région, il est mis en avant que son coût (170 MF HT dont 125 MF HT pour la seconde tranche, soit $7700 \mathrm{~F} \mathrm{HT}$ le mètre carré - $91000 \mathrm{FHT}$ pour la seule seconde tranche - soit un coût de 43 F HT par habitant) est réduit par rapport aux autres hôtels de région, notamment Aquitaine (180 MF HT soit $12800 \mathrm{~F} \mathrm{HT} \mathrm{au} \mathrm{mètre} \mathrm{carré} \mathrm{soit} \mathrm{un} \mathrm{coût} \mathrm{de} 68 \mathrm{~F}$ par habitant), LanguedocRoussillon (95 MF HT soit 8900 F HT au mètre carré, soit un coût de 49 F par habitant), Pays de la Loire (120 MF HT soit 6100 F HT au mètre carré, soit un coût de 41 F HT par habitant), PoitouCharentes (60 MF HT, soit 10300 F HT au mètre carré, soit un coût HT de 38 F par habitant) (hôtel de région. $2^{\mathrm{e}}$ tranche. Argumentaire, s.d. circa 1987-1991, ARPACA 35 W 97).

73. - «L'hôtel de région est un monument : il manifeste le nouveau pouvoir régional; il est la pièce maitresse de la place d'Aix", mais s'élevant face à l'arc de triomphe de Michel-Robert Penchaud, il doit être conçu de telle sorte que « les deux monuments se valorisent l'un l'autre » (Région PACA, hôtel de Région $2^{\mathrm{e}}$ tranche. Dossier de consultation des concepteurs. Programme, décembre 1986, ARPACA 35 W 95). Les prescriptions d'Adrien Fainsilber (né en 1932), que la Ville de Marseille avait chargé d'étudier la requalification de la place d'Aix, sont transcrites dans le même document. L'architecte-conseil plaide pour un marqueur urbain, exprimant sa propre identité, et qui, par le raffinement de son architecture, la simplicité et l'évidence de ses formes, les matériaux utilisés, soit un édifice prestigieux possédant un caractère de pérennité.

74. - « Hôtel de Région ». Marseille, Architecture à Marseille depuis un siècle, $\mathrm{n}^{\circ}$ 219, décembre 2007, p. 96-97. Claude Parent explique à plusieurs reprises qu'il entend transmettre, par les volumes mêmes du bâtiment, une idée de force et de résistance et inspirer, par l'utilisation du béton, la pérennité.

75. - TILMONT, Michèle. Art. cit., p. 9-10.

\section{RÉSUMÉS}

Cet article envisage le rapport entre architectures et lieux de pouvoir tel que ce dernier s'est redéfini à Marseille, à l'aune de la décentralisation, entre le milieu des années 1980 et le milieu des années 1990. Cette décennie a en effet vu la construction d'un nouvel hôtel de région réalisé en deux tranches (1984-1986, arch.: Jean-Michel Battesti ; 1987-1991, arch.: Claude Parent, Christian Biaggi, Bruno Maurin) et d'un hôtel de département (1990-1994, arch. : William Alsop, John Lyall). Ces deux bâtiments, qui mobilisent des partis architecturaux très différents, viennent incarner l'affirmation du pouvoir de collectivités locales directement issues des lois de décentralisation de 1982 (conseil régional et conseil départemental en l'occurrence), cela dans un paysage que ces édifices contribuent largement à renouveler (requalification du quartier de la Butte-aux-Carmes pour le premier et de Saint-Just pour le second). Ils ont en outre en commun d'avoir été programmés et conçus à la faveur de la loi sur la maîtrise d'ouvrage publique (loi MOP, 1985) qui, par la généralisation des concours, entendait favoriser l'accès de nouveaux maîtres d'œuvre à la commande publique, l'inventivité architecturale et, in fine, la qualité des constructions. Ce contexte particulier invite à s'interroger sur la place qu'occupent ces édifices dans la ville. Il conduit surtout à poser la question de la dimension symbolique de leur architecture, à un moment où le concept d' « équipement public », qui avait prévalu au cours des Trente Glorieuses, tend à s'effacer au profit de celui d'" architecture publique ", glissement 
sémantique révélateur de la manière dont les maîtres d'ouvrage se saisissent de l'architecture pour affirmer leur emprise et définir leur image.

This article considers the relationships between architecture and places of power as they were redefined in Marseille, as a result of decentralisation policies between the mid-1980s and the mid-1990s. This decade saw the construction of a new 'hôtel de région' built in two campaigns (1984-1986, architects Jean-Michel Battesti, 1987-1991, architect Claude Parent, Christian Biaggi, Bruno Maurin) and a departmental hotel (1990-1994, architect William Alsop, John Lyall). These two buildings, of very different architectural design, embody the reinforcement of the power of local authorities resulting from the decentralisation laws of 1982 (regional council and departmental council in this case). The environments of these new buildings were largely modified by these buildings: requalification of the district of Butte-aux-Carmes for the first and of Saint-Just for the second. They also share the characteristic of having been programmed and designed under the Public Ownership Act (Loi MOP, 1985) which, through the generalisation of public competitions, was intended to promote the access to public works for new architects, the architectural inventiveness and, ultimately, the quality of buildings. This particular context invites us to question the place of these buildings in the city. It leads in particular to the question of the symbolic dimension of their architecture, while the concept of 'public equipment', which had prevailed during the Thirty glorious years, tends to disappear in favour of 'public architecture', a semantic shift which reveals how the local authorities used architecture to assert their influence and to define their image.

\section{INDEX}

Mots-clés : architecture publique, commande publique, édifice public, architecture administrative, Hôtel de département, Hôtel de région, Loi sur la maîtrise d'ouvrage publique (loi MOP), Mission interministérielle sur la qualité des constructions publiques (MIQCP), décentralisation, collectivité territoriale, Conseil général, Conseil régional, département, région, concours d'architecture, concours international d'architecture, Grand Prix national d'architecture, William Alsop, Daniel Badani, Jean-Michel Battesti, Christian Biaggi, Ricardo Bofill, Jean-Pierre Buffi, Roland Castro, Paul Chemetov, Olivier Dugas, Norman Foster, Massimiliano Fuksas, Patrice Goulet, Gérard Grandval, Greenhill-Jenner, Borja Huidobro, Alexis Josic, Françoise-Hélène Jourda, Lucien Kroll, John Lyall, Giorgio Macola, Bruno Maurin, John Miller, Manolo Nunez-Yanowsky, Claude Parent, Gilles Perraudin, Paolo Portoghesi, Fernando Ramos, Rudy Ricciotti, Alain Sarfati, Denis Sloan, Francis Soler, Pascal Urbain, Fernando Urquito, Gino Valle, Claude Vasconi, Jean-Paul Viguier, Peter Wilson

Keywords : public architecture, public order, public building, administrative architecture, departmental hotel, regional hotel, law on public project ownership (MOP Law), inter-ministerial mission on the quality of public buildings (MIQCP), decentralisation, territorial collectivity, general council, regional council, department, region, architectural competition, international architectural competition, national grand prix for architecture, William Alsop, Daniel Badani, Jean-Michel Battesti, Christian Biaggi, Ricardo Bofill, Jean-Pierre Buffi, Roland Castro, Paul Chemetov, Olivier Dugas, Norman Foster, Massimiliano Fuksas, Patrice Goulet, Gérard Grandval, Greenhill-Jenner, Borja Huidobro, Alexis Josic, Françoise-Hélène Jourda, Lucien Kroll, John Lyall, Giorgio Macola, Bruno Maurin, John Miller, Manolo Nunez-Yanowsky, Claude Parent, Gilles Perraudin, Paolo Portoghesi, Fernando Ramos, Rudy Ricciotti, Alain Sarfati, Denis Sloan, Francis Soler, Pascal Urbain, Fernando Urquito, Gino Valle, Claude Vasconi, Jean-Paul Viguier, Peter Wilson 


\section{AUTEUR}

\section{ÉLÉONORE MARANTZ}

Maître de conférences en histoire de l'architecture contemporaine, Université Paris 1 PanthéonSorbonne, EA 4100 Histoire culturelle et sociale de l'art (HiCSA) eleonore.marantz-jaen@univparis1.fr 